\title{
Optical near-field imaging and nanostructuring by means of laser ablation
}

\author{
Johannes Boneberg and Paul Leiderer*
}

\begin{abstract}
In this review we consider the development of optical near-field imaging and nanostructuring by means of laser ablation since its early stages around the turn of the century. The interaction of short, intense laser pulses with nanoparticles on a surface leads to laterally tightly confined, strongly enhanced electromagnetic fields below and around the nano-objects, which can easily give rise to nanoablation. This effect can be exploited for structuring substrate surfaces on a length scale well below the diffraction limit, one to two orders smaller than the incident laser wavelength. We report on structure formation by the optical near field of both dielectric and metallic nano-objects, the latter allowing even stronger and more localized enhancement of the electromagnetic field due to the excitation of plasmon modes. Structuring with this method enables one to nanopattern large areas in a one-step parallel process with just one laser pulse irradiation, and in the course of time various improvements have been added to this technique, so that also more complex and even arbitrary structures can be produced by means of nanoablation. The near-field patterns generated on the surface can be read out with high resolution techniques like scanning electron microscopy and atomic force microscopy and provide thus a valuable tool-in conjunction with numerical calculations like finite difference time domain (FDTD) simulations-for a deeper understanding of the optical and plasmonic properties of nanostructures and their applications.
\end{abstract}

Keywords: nanostructuring; optical near field; laser ablation; plasmonics

Boneberg J, Leiderer P. Optical near-field imaging and nanostructuring by means of laser ablation. Opto-Electron Sci 1, 210003 (2022).

\section{Introduction and background}

Small particles at surfaces have become an important research topic ever since nanotechnology has developed to one of the modern key technologies. Often these particles are unwanted contaminants, e.g. in micro- and nanoelectronics. On the other hand, nano-sized particles can also be used for the generation of surface structures, as will be shown in this review. We give here, from a very personal perspective, a brief survey of the history of nanostructuring surfaces by means of the optical near fields of such small particles which are illuminated by short laser pulses. In this section we start with the background of this topic, where a crucial role was played by the tech- nique of laser cleaning, out of which the near-field nanostructuring developed. In sections Optical near fields of dielectric nanostructures and Optical near fields of plasmonic nanostructures we will then discuss the formation of nanostructures by laser ablation in the optical near fields of dielectric and plasmonic nanoparticles, respectively.

The investigation of small particles on a substrate, interacting with intense light fields, started around 1990. At that time surface contamination by particulates was one of the most serious problems faced by the microelectronic industry, because a major part of the yield losses in Integrated Circuits (ICs) was attributed to it.

Department of Physics, University of Konstanz, Konstanz 78457, Germany.

*Correspondence: P Leiderer, Email: paul.leiderer@uni-konstanz.de

Received: 13 May 2021; Accepted: 30 July 2021; Published online: 25 November 2021

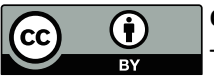

Open Access This article is licensed under a Creative Commons Attribution 4.0 International License.

To view a copy of this license, visit http://creativecommons.org/licenses/by/4.0/.

C The Author(s) 2022. Published by Institute of Optics and Electronics, Chinese Academy of Sciences. 
Although at that time the characteristic length scale of IC technology was relatively large compared to today's standards $(>500 \mathrm{~nm})^{1}$, the available cleaning techniques based on wiping and brushing, ultrasonics and liquid chemicals were not efficient enough to reliably remove particles with a size as small as $100 \mathrm{~nm}$, which could be detrimental for the production of ICs at that time ${ }^{2,3}$. Therefore, new gentle and also environmentally friendly cleaning techniques were sought for.

A promising technique in this direction, published in 1991 by the group of A.C. Tam, was the so-called laser cleaning $^{2,3}$. The basic idea of this concept was to heat the substrate which was to be cleaned by a nanosecond laser pulse. The rapid thermal expansion of the substrate will then accelerate particles on the surface, and when the expansion comes to a halt at the end of the heating process, the particles detach from the surface due to inertia forces strong enough to overcome the forces of particle adhesion. Already in these early investigations, this effect of particle removal was sometimes enhanced by a thin liquid film, e.g. a water-alcohol mixture, condensed onto the substrate immediately before the laser pulse. As the substrate is momentarily heated, the temperature of the film also rises, until bubble nucleation at the solid-liquid interface takes place, and the subsequent explosive evaporation of the liquid enforces the removal of the contaminants. This latter mechanism was later termed "Steam Laser Cleaning" (SLC), while the first one was called "Dry Laser Cleaning" (DLC). An example for the cleaning action by this method is shown in Fig. 1. Altogether, high cleaning efficiencies close to 100 percent were reached at high enough laser intensities. (It should be mentioned that parallel to this SLC concept, which relied on the indirect heating of the liquid film via the substrate, an alternative scheme was developed in the group of S. Allen ${ }^{4}$. There the liquid film was heated directly using a $\mathrm{CO}_{2}$ laser with a wavelength that is strongly absorbed by the liquid. Also in this case, good cleaning results due to the explosive evaporation of the film were reported.)

In the years following these first developments, the processes occurring during both DLC and SLC were investigated in more detail. One aspect was the mechanism of bubble nucleation at the liquid-solid interface, which was studied in a sequence of papers by Yavas et al. ${ }^{5-8}$. Also, the thermal expansion of the substrate and the concomitant acceleration of the surface was measured with nanosecond time resolution ${ }^{9}$. The resulting ac-
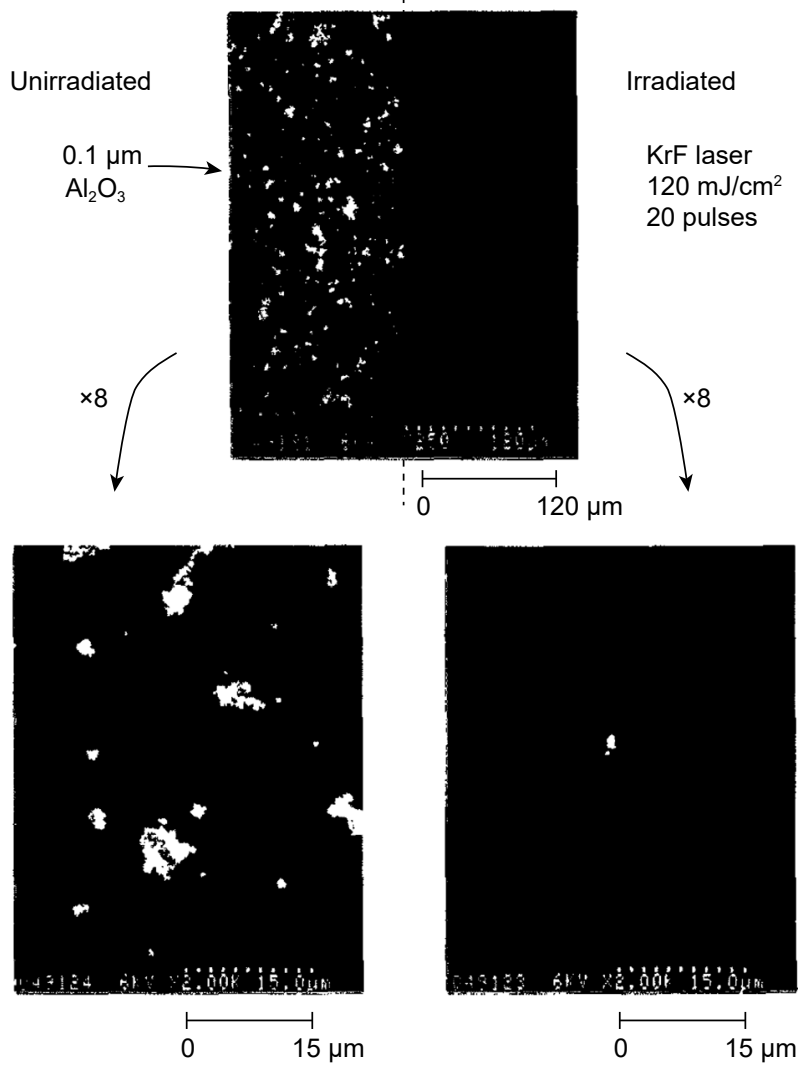

Fig. 1 Scanning electron microscope (SEM) photos showing SLC of $0.1-\mu \mathrm{m}$ alumina particles from a Si surface (with water film assistance). The $\mathrm{KrF}$ laser (pulse duration $16 \mathrm{~ns}$, wavelength $\lambda=248 \mathrm{~nm}$ ) had a fluence of $120 \mathrm{~mJ} / \mathrm{cm}^{2}$, and 20 pulses were used. Figure reproduced with permission from ref. ${ }^{3}$, American Institute of Physics.

celerations were found to be in the range of $10^{7} \mathrm{~m} / \mathrm{s}^{2}$, i.e. 6 orders of magnitude higher than the acceleration due to gravity, but still somewhat too small to overcome the expected adhesion forces ${ }^{10}$. One of the reasons for this discrepancy will be discussed at the end of this section.

In 1995, a joint European project was initiated, dedicated to various forms of laser cleaning, in which groups from Austria, France, Germany, Greece and Spain collaborated ${ }^{11}$. The aims of this project were relatively broad, reaching from cleaning industrial oxidized surfaces to the restoration of art work, but one central topic was laser cleaning of delicate surfaces like silicon wafers from nanoparticles ${ }^{11}$. Systematic comparisons between DLC and SLC were carried out ${ }^{12}$, in which lasers with different wavelengths from UV to near IR and with pulse durations ranging from the nanosecond down to the femtosecond regime were tried out. A major step towards a quantitative understanding was also replacing the so far mostly used test contaminants, irregularly 
shaped powders of alumina or silica, by well-defined spherical particles with a monodisperse size distribution ${ }^{12,13}$. Such particles are available with various diameters as colloidal suspensions which can be spincoated on the test surface.

An example of Polystyrene (PS) spheres with a diameter of $480 \mathrm{~nm}$ is presented in Fig. 2. In the DLC experiments, these samples were irradiated with the cleaning laser pulse in ambient atmosphere; for the SLC measurements an additional burst of water-alcohol vapor, supplied through a nozzle, was condensed onto the Si substrate before the illumination. The cleaning efficiency was either evaluated by simply counting the number of particles in the irradiated area before and after the laser pulse, or by measuring the light scattering from the remaining particles ${ }^{14}$.

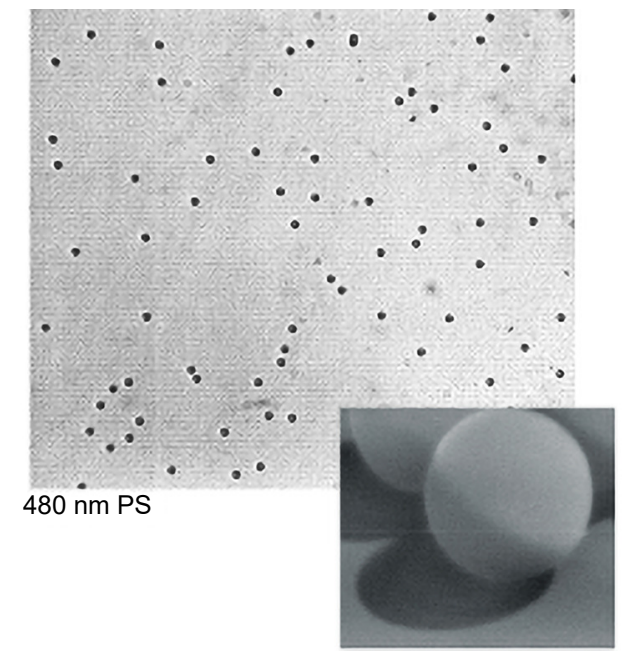

Fig. 2 | SEM image $\left(50 \times 50 \mu \mathrm{m}^{2}\right)$ of $\mathbf{4 8 0} \mathrm{nm}$ PS particles spin coated on a silicon wafer. The insert shows a blow-up demonstrating the spherical shape of these colloid particles. Figure reproduced with permission from ref. ${ }^{12}$, Spring Nature.

Representative results for the cleaning efficiency are shown in Fig. 3 for the case of SLC. The data reveal a threshold fluence for the onset of cleaning $\left(110 \mathrm{~mJ} / \mathrm{cm}^{2}\right)$, and nearly complete cleaning is achieved around a fluence of $200 \mathrm{~mJ} / \mathrm{cm}^{2}$, which is well below the onset of melting of the (bare) Si surface for 8 ns pulses at the used wavelength of $532 \mathrm{~nm}$. The efficiency turned out to be essentially independent of particle size and material, as it is expected that the explosive evaporation of the liquid layer is the dominating detachment mechanism.

This is different for the case of DLC, as plotted in Fig. 4, where SLC and DLC data are compared. First of all, the cleaning threshold for DLC is distinctly higher than that for SLC, and the efficiency reaches just $50 \%$ at a

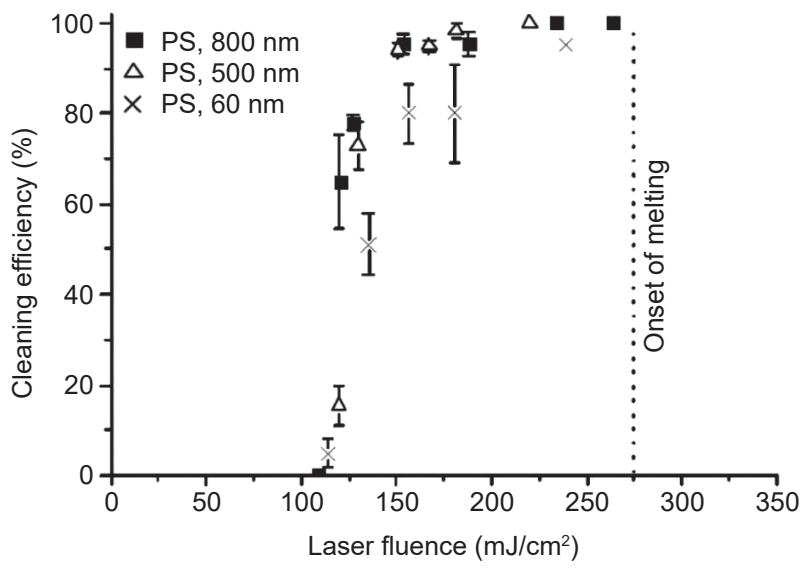

Fig. 3 | Experimental SLC efficiency for various PS spheres vs. laser fluence. The number of cleaning pulses from a Nd:YAG laser $(\lambda=532 \mathrm{~nm}, \mathrm{FWHM}=8 \mathrm{~ns})$ was 20 in each case. The cleaning threshold is size-independent, and the efficiency exhibits a steep increase above the onset of cleaning $\left(110 \mathrm{~mJ} / \mathrm{cm}^{2}\right)$. The same threshold is obtained when only 1 cleaning pulse is applied. Figure reproduced with permission from ref. ${ }^{15}$, SPIE.

laser fluence where the Si surface starts to melt. What is more, the DLC data depended crucially on the humidity in the air of the laboratory. This was already mentioned in the early work of laser cleaning ${ }^{3}$, but it became particularly clear in the course of a collaboration between the Data Storage Institute in Singapore and the Konstanz lab in Germany. On a dry winter day in Konstanz the DLC efficiency was observed to be considerably lower than for the identical sample in Singapore. This could be ascribed to the significantly higher humidity in the Singapore lab, which led to more pronounced capillary condensation of a liquid water meniscus around the area where the particle touches the surface. Upon irradiation with the laser pulse, this gives rise to explosive evaporation, thus the term "Dry Laser Cleaning" is not really justified in ambient air, because of the partial contribution of the SLC mechanism. This was corroborated by similar cleaning experiments under high vacuum conditions, in which a further efficiency reduction compared to DLC in ambient atmosphere was observed. Results qualitatively similar to the nanosecond laser cleaning experiments discussed so far were found for picosecond laser pulses, the absolute cleaning threshold values being somewhat reduced for the ps compared to the ns pulses ${ }^{12,15}$.

The state of the interpretation of DLC at the end of the 1990s thus was that the detachment of particles is due to the combined action of acceleration (or rather deceleration) of the substrate surface and the explosive evaporation of adsorbed water, the contributions of these two 
processes depending on the details of the experiment. In several theoretical investigations, the effect of the thermal expansion was modelled; some of these studies came to the conclusion that the mechanical model could describe the experimental results reasonably well, whereas others found that the predicted mechanical forces were too small to account for the experimental cleaning thresholds ${ }^{10,16-20}$.

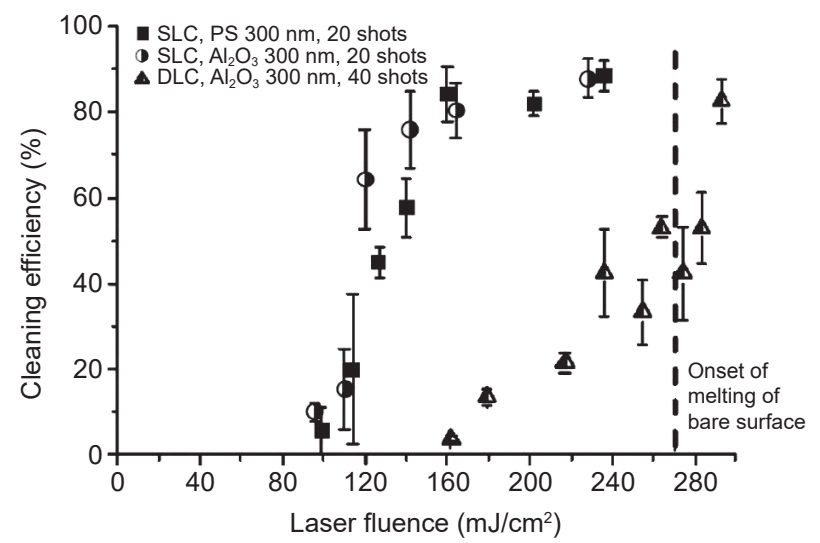

Fig. 4 | Cleaning efficiencies for ns DLC (40 laser shots each) and SLC (20 shots each). The DLC experiment was carried out in "normal" laboratory atmosphere, without the application of an additional vapor pulse as for the SLC experiment in Fig. 3. Figure reproduced with permission from ref. ${ }^{15}$, SPIE.

\section{Optical near fields of dielectric nanostructures}

In the following we will mainly consider commercial silicon wafers as the substrate, on the one hand because these wafers were one of the main objects of laser cleaning $^{11}$, but also because they are very smooth, and therefore any influence of the particles on the ablation process is more readily visible than for, e.g., evaporated metal films.

We present here the state of the art at the beginning of the year 2000, when these phenomena were discussed at a conference "High Power Laser Ablation III", held in April 2000 in Santa Fe, USA.

\section{Laser-induced surface damage}

Most of the experiments up to that point had been carried out with laser pulses in the ns range. In order to evaluate the potential of DLC and SLC for the cleaning of commercial silicon wafers, the studies from then on systematically included also shorter laser pulses, because as mentioned above - the intensity window between cleaning threshold and melting of the silicon was somewhat broader for ps lasers, an important aspect for po- tential applications.

In the experiments with ps pulses (and somewhat later also with fs pulses) it turned out that the picture of DLC outlined above was not complete: when surfaces cleaned in this way were carefully inspected by SEM or AFM, surface defects in the form of small holes became visible, as shown in Fig. 5 for $800 \mathrm{~nm}$ PS spheres on a Si substrate, irradiated with a $30 \mathrm{ps}$ pulse $\mathrm{e}^{15}$. A similar observation of surface damages, but irregular in shape, was observed at about the same time in DLC studies of glass with nanosecond UV laser pulses, where $\mathrm{Al}_{2} \mathrm{O}_{3}$ powder was used as test contaminant ${ }^{21,22}$.

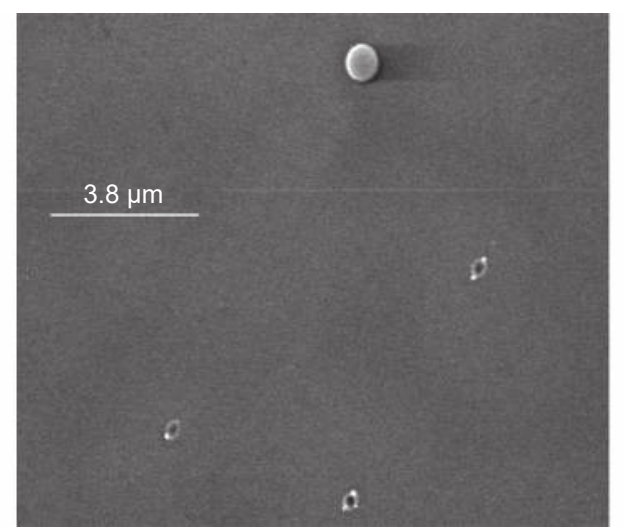

Fig. 5 | Scanning electron micrograph of a cleaned area (DLC, $\lambda=583 \mathrm{~nm}$, FWHM $30 \mathrm{ps}$ ) in a sample contaminated with $800 \mathrm{~nm}$ PS spheres. Elliptical holes can be found over the illuminated region, and also a remaining particle can be seen. Figure reproduced with permission from ref. ${ }^{15}$, SPIE.

It was suggestive that the origin of these surface damages were the optical near fields of the test particles. This interpretation was supported by Mie calculations ${ }^{23}$, which showed that the intensity underneath the particles can be enhanced by an order of magnitude or even more (depending on the particle size, Fig. 6), and is thus locally well above the ablation threshold for the Si substrate,

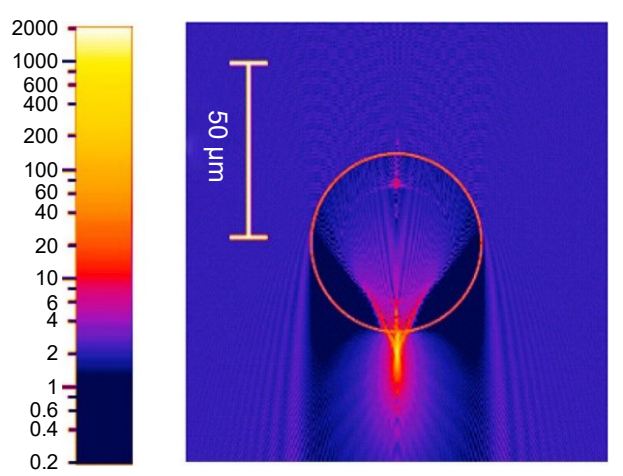

Fig. 6 | Mie calculation of the optical near field of a spherical transparent particle with a diameter $\boldsymbol{d} \gg$ > laser wavelength $\lambda$. The scale on the color code gives the enhancement factor. 
when the incident laser fluence is above the cleaning threshold. The nanoholes in the surface are therefore nanoscopic ablation craters generated by the optical near field. At about the same time, Lu et al. and Zheng et al. considered the optical near field of a small transparent sphere in their investigations of laser-induced particle removal from silicon wafers ${ }^{17,19}$. In these papers only the enhancement of the thermal expansion of the substrate, and no laser ablation, was discussed.

At that point it was not clear yet whether these holes are just a by-product of the irradiation process, or whether this local ablation with its additional pressure acting upon the particle is crucial for the particle removal. In an additional experiment, the initial positions of the spheres on the wafer were therefore marked by evaporating a thin $(10 \mathrm{~nm}) \mathrm{SiO}_{2}$ layer after the deposition of the particles, but before the laser cleaning. After the removal of the particles, their original position could thus be determined by a contrast in the SEM pictures, as seen in Fig. 7.

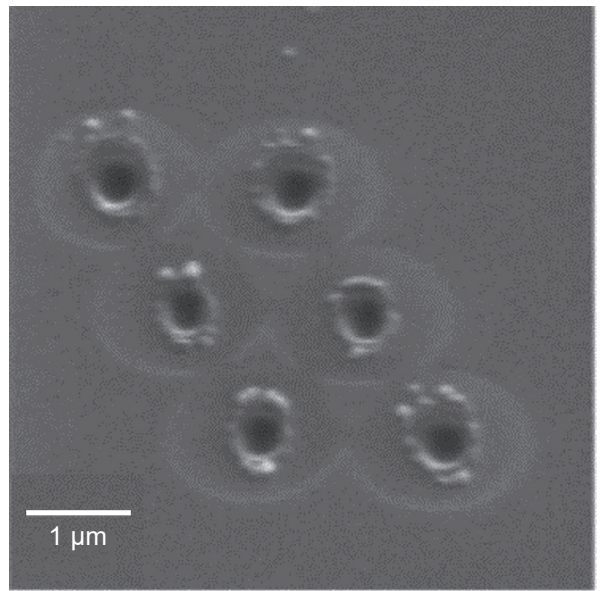

Fig. 7 | Holes generated during DLC of a silicon surface with a fs laser pulse $(150 \mathrm{fs}, \lambda=800 \mathrm{~nm})$ by an aggregate of six $1700 \mathrm{~nm}$ PS spheres. Figure reproduced with permission from ref. ${ }^{15}$, SPIE.

The circular disk-like, slightly brighter regions in Fig. 7 , which are due to the thinner (natural) oxide film on the silicon, mark the "footprint" of the spherical particles. It was found that every such footprint had an ablation hole in its center, and that in the fs and ps DLC experiments the removal of particles was always accompanied by the appearance of such holes. Vice versa, no holes were found under particles that had not been removed by the laser pulse ${ }^{24}$. Hence the ablation process could in these cases be directly related to the ejection of material from the silicon substrate, which then also leads to the observed crater formation.

This was further corroborated by a comparison of vertical and inclined irradiation of the test particles. Figure 8(a) shows an example where a $1.7 \mu \mathrm{m}$ sphere was irradiated at an angle of incidence of $45^{\circ}$ from the left. The ablation hole is therefore not in the center, but at the right edge of the particle's footprint. Another example is given in Fig. 8(b), where an aggregate of 3 particles, also irradiated at $45^{\circ}$, detached only partly. Two of the spheres generated ablation holes, and the traces of the substrate material deposited on the spheres due to the ablation are clearly visible.
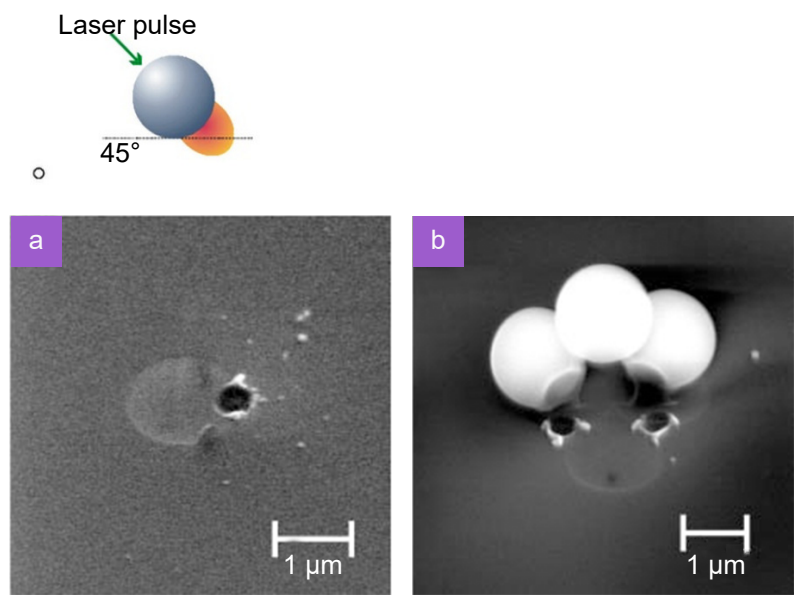

Fig. 8 | Holes generated during DLC of a silicon surface with a fs laser pulse (150 fs, $\lambda=800 \mathrm{~nm}$ ). (a) laser beam incident at an angle of $45^{\circ}$ from the left side. (b) $45^{\circ}$ incidence from the back. Figure reproduced with permission from ref. ${ }^{27}$, John Wiley and Sons. A more detailed description of ablation effects upon inclined irradiation of nanospheres has been presented by Wang et al. ${ }^{131}$.

\section{Influence of particle size}

Similar holes were also found for smaller particles, but with somewhat different shape. The essential parameter is the ratio between the particle diameter $d$ and the laser wavelength $\lambda$. For $d / \lambda>1$, as in the examples shown so far, the particle acts essentially like a spherical microlens. For smaller sphere diameters, the character of the optical near field gradually changes towards the field of a dielectric dipole. This is shown in Fig. 9. At the same time, the smaller the ratio $d / \lambda$ is, the more the field enhancement is reduced. As a result, the incident intensity necessary for particle detachment is expected to increase. Experimentally, this was confirmed: while for $1700 \mathrm{~nm}$ spheres the cleaning threshold was $11 \mathrm{~mJ} / \mathrm{cm}^{2}$, an incident flux of 25 and $80 \mathrm{~mJ} / \mathrm{cm}^{2}$ was necessary to remove $800 \mathrm{~nm}$ and $320 \mathrm{~nm}$ particles, respectively, using femto- 

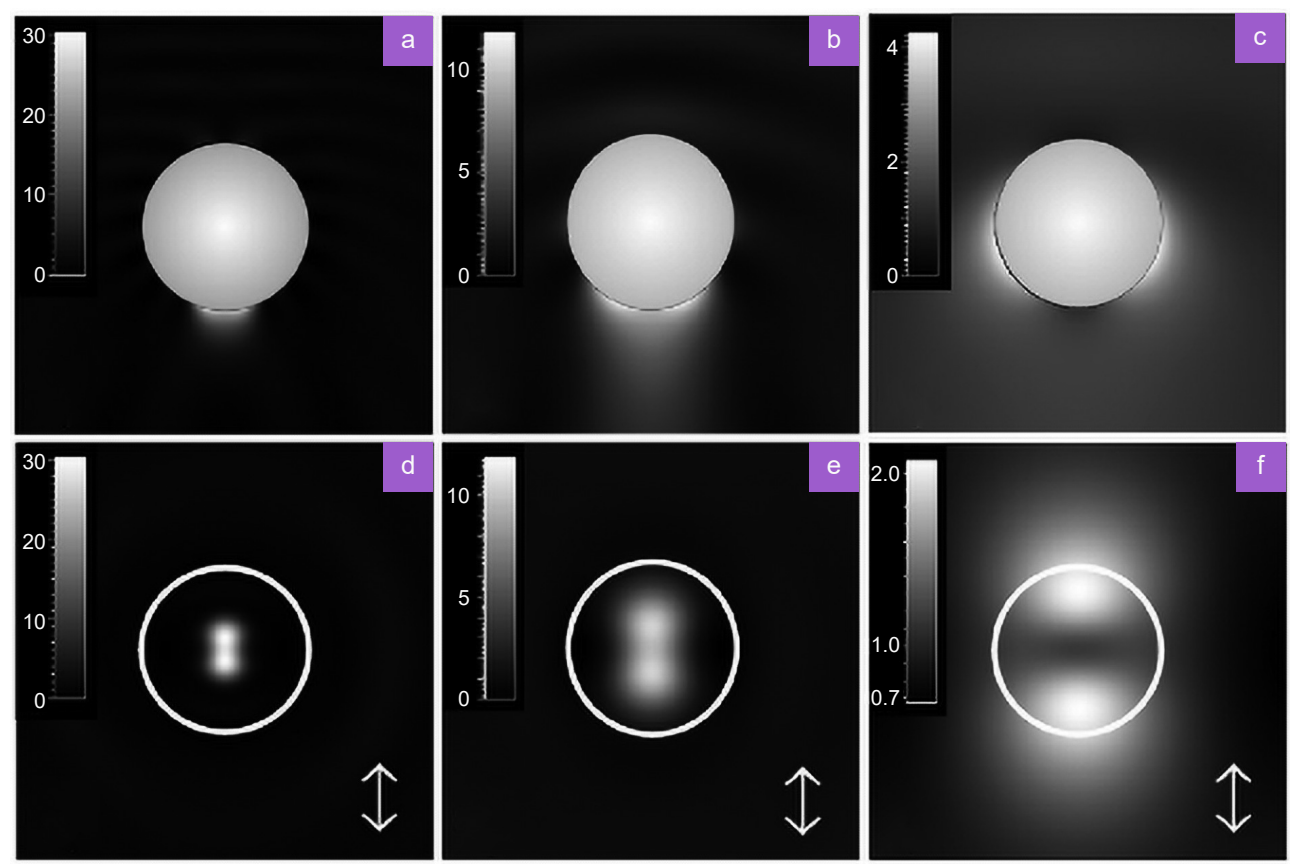

Fig. 9 | Calculated field intensities for spheres (PS, refractive index $\boldsymbol{n}=1.6$ ) that are irradiated at $\boldsymbol{\lambda}=\mathbf{8 0 0} \mathrm{nm}$. The diameters of the spheres are $1700 \mathrm{~nm}(\mathbf{a}, \mathbf{d}), 800 \mathrm{~nm}(\mathbf{b}, \mathbf{e})$ and $320 \mathrm{~nm}(\mathbf{c}, \mathbf{f})$. Plotted is the intensity in a cross section as seen from the side (a-c) and in the plane of the substrate surface as seen from above $(\mathbf{d}-\mathbf{f})$. The light field enters from the top, and the polarization vector of the electric field is indicated by an arrow. The displayed areas are $5100 \mathrm{~nm} \times 5100 \mathrm{~nm}, 2400 \mathrm{~nm} \times 2400 \mathrm{~nm}$, and $960 \mathrm{~nm} \times 960 \mathrm{~nm}$, respectively. Figure reproduced with permission from ref. ${ }^{15}$, SPIE.

second laser pulses with $\lambda=800 \mathrm{~nm}$ and FWHM $=150 \mathrm{fs}^{24}$.

Experimentally, the asymmetry due to the dipole character of the optical near field for the smaller particles could already be guessed from the slightly elliptical hole structures in Fig. 5. An example where the dipolar character is more obvious, for a $d / \lambda$ value of 0.4 , is depicted in Fig. 10. The dumbbell-like shape of the hole in Fig. 10(b), determined by AFM, clearly reflects the intensity distribution of the near field in Fig. 10(a). In addition, the hole is surrounded by a circular elevated rim. It was shown that the rim consists of $\mathrm{SiO}_{x}$, it is thus material which is ablated, backscattered from the particle during the detachment, and is partly oxidized during this process. The similarity between the simulated and the experimental pattern in Fig. 10 suggested that local ablation of the smooth silicon substrate can be used to image the optical near field distribution of nanoscopic objects. This will be further discussed in Section Optical near fields of plasmonic nanostructures.

\section{Temporal development of near-field induced structure formation}

All the images of near-field induced structures shown so far represent the final result of the ablation process. In order to understand the structuring in detail, however, it

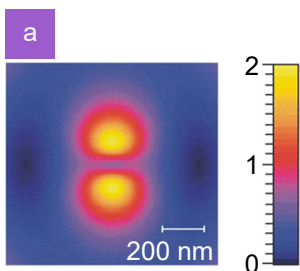

Mie calculation

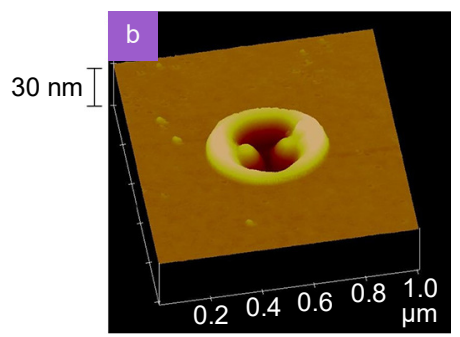

Fig. 10 | Near-field of a colloidal sphere $320 \mathrm{~nm}$ in diameter. (a) Mie calculation of the optical near-field intensity in the substrate plane. (b) AFM picture of the silicon substrate under the colloidal sphere after irradiation with a femtosecond laser pulse (150 fs, $\lambda=$ $800 \mathrm{~nm}$ ). The particle itself has been removed due to material ablation. Figure reproduced with permission from ref. ${ }^{85}$, AIP Publishing.

is also desirable to investigate this process with high time resolution. For accessing the relevant time scale, femtosecond microscopy is necessary. Figure 11 shows a sequence of frames, obtained by a pump-probe technique, which illustrates the near-field induced formation of a hole generated in a Si substrate by irradiating a $7.9 \mu \mathrm{m}$ diameter silica sphere with a fs laser pulse ${ }^{25}$. Already for a delay of $200 \mathrm{fs}$, one can observe the formation of a bright spot, located adjacent to the particle position, which is interpreted as evidence for the formation of a dense electron-hole plasma. At 4 ps delay, this formerly bright region turns dark, indicating that strong ablation is already 

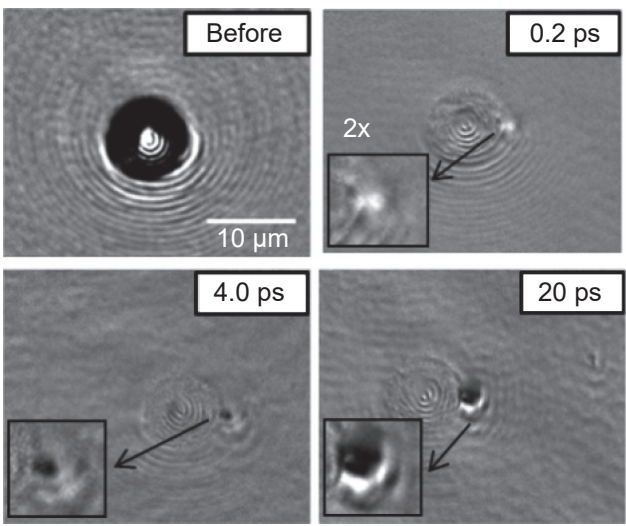
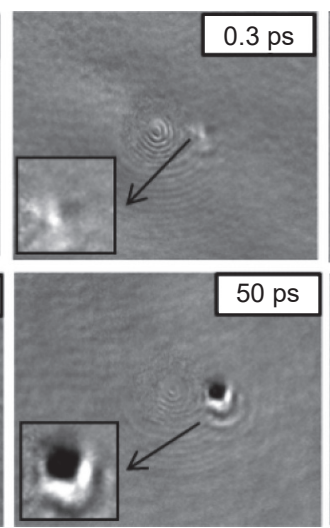
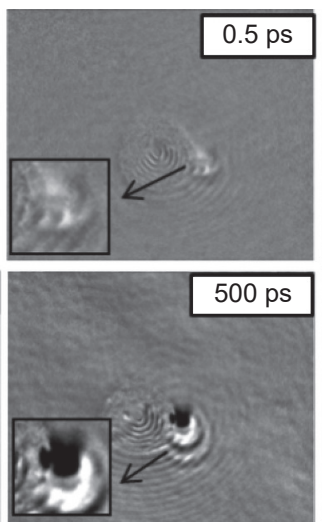

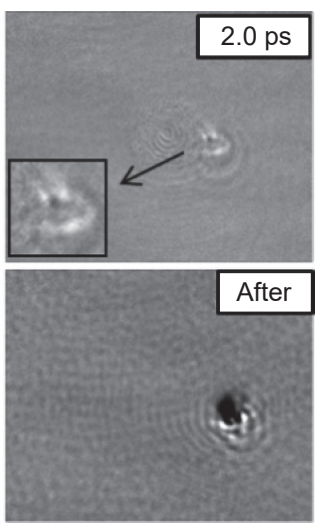

Fig. 11 | Femtosecond-resolved ablation dynamics of $\mathrm{Si}$ in the near field of a small dielectric sphere, appearing as a black disk in the top left frame. Shown are surface reflectivity images at the particle location for different time delays (indicated in the upper right

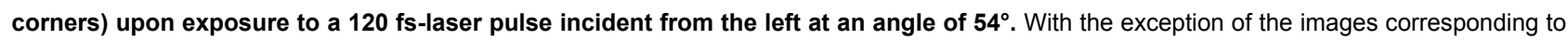
the surface before and after the arrival of the laser pulse, the images have been normalized to an image obtained blocking the pump pulse in order to minimize the scattering effects caused by the $7.9 \mu \mathrm{m}$-diameter particle. A zoom $(2 \times)$ has been applied to the relevant part of the image and pasted as an inset. Figure reproduced from ref. ${ }^{25}$, under a Creative Commons Attribution License 2.0.

taking place, and after some 10 ps the image hardly changes. The authors conclude from their study, by comparison with "usual" far-field ablation, that in the tightly focused near-field region the onset of strong ablation is shifted to shorter times.

When laser pulses longer than a few picoseconds are used for structuring, the character of the structure formation changes, because on the ns time scale lateral heat flow in the substrate cannot be neglected any more. The thermal diffusion length $l=2(D \tau)^{1 / 2}$ ( $D$ is the thermal diffusion coefficient and $\tau$ is the laser beam dwell time) reaches the structure size. For a silicon substrate, e.g., one finds an estimated value $l \approx 1 \mu \mathrm{m}$ for $\tau=8 \mathrm{~ns}$. Moreover, melting and lateral flow of the molten substrate become important. It is therefore to be expected that the near-field focusing of ns pulses leads to structures which are smeared out, compared to the fs counterpart. This is indeed the case, as illustrated in Fig. 12.
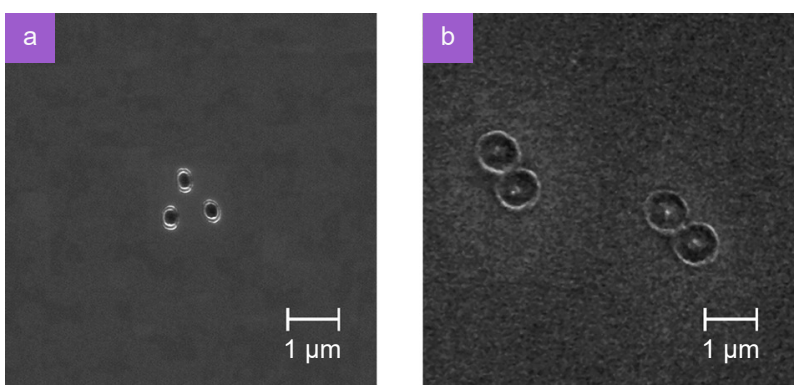

Fig. 12 | Near-field induced holes created by irradiating clusters of $\mathbf{8 0 0 ~ n m ~ P S ~ s p h e r e s ~ o n ~ s i l i c o n . ~ ( a ) ~ T r i m e r ~ i r r a d i a t e d ~ w i t h ~ a ~} 100 \mathrm{fs}$ pulse. (b) Two dimers irradiated with an 8 ns pulse. The wavelength was in both cases $\lambda=800 \mathrm{~nm}$. Figure reproduced with permission from ref. ${ }^{33}$, SPIE.

\section{Particle-enhanced laser writing and nanostructuring of regular hole arrays}

Once it was clear that the observed nano-holes on the laser-cleaned Si surfaces were caused by the optical near fields of the test particles, it was a relatively small step toward using this effect also for intentional nanopatterning of surfaces ${ }^{26,27}$. If one is not interested in a random configuration of holes, as it would be generated by the spatial distribution of spheres in Fig. 2, but would rather produce a regular array of holes, colloid spheres can be relatively easily applied also for that purpose, since they can aggregate (due to their monodispersity) to self-organized, densely packed monolayers with hexagonal symmetry.

The tendency of these spheres to form regular, densely-packed aggregates in the drying process is already visible in Fig. 7, where the holes were generated by a cluster of six particles. Under appropriate conditions, one can prepare ordered arrays on a scale of $\mathrm{cm}^{228-31}$, which then can be used to generate millions of nanoholes with one laser pulse irradiation. A detailed fraction of such a patterned surface, $\mathrm{Si}$ in this case, is shown in Fig. 13(a), where in the upper part the colloid spheres are still present. The diameter, depth and distance of the holes can be varied over a broad range by choosing the right colloid sphere size and the laser intensity.

This technique has been used by a number of groups $^{32-45}$. Figure 13(b) shows a pattern, again on a $\mathrm{Si}$ substrate, with holes as small as $57 \mathrm{~nm} \mathrm{FWHM}{ }^{41}$, and even smaller holes down to $30 \mathrm{~nm}$ in diameter have been 

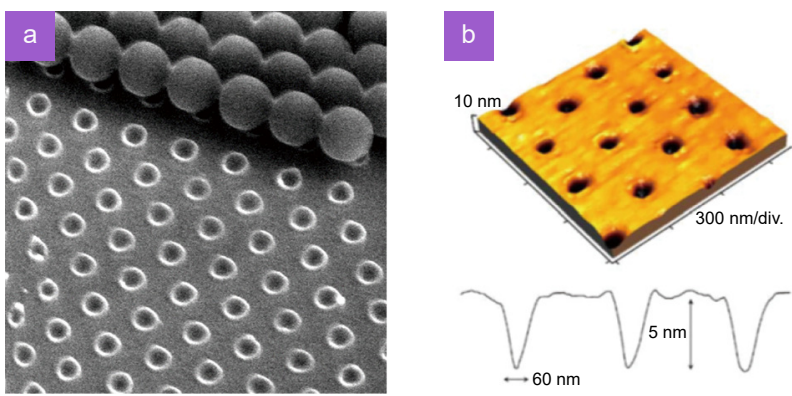

Fig. 13 | (a) Nanohole pattern generated by illuminating an ordered array of PS microspheres with a single laser pulse $(\tau=150 \mathrm{fs}, \lambda=$ $800 \mathrm{~nm}$ ). Some remaining spheres are also seen. (Sphere diameter $800 \mathrm{~nm}$; similar images are shown in ref. ${ }^{33}$ ). (b) Silicon nanoholes fabricated on a (100) Si surface by using a single-shot 265.7-nm Ti:sapphire laser radiation ( $300 \mathrm{fs}$, fluence $15 \pm 3.5 \mathrm{~mJ} / \mathrm{cm}^{2}$ ) together with a regular lattice of $\mathrm{SiO}_{2}$ microspheres $(r=150 \mathrm{~nm})$. The width of the holes at FWHM is $57 \pm 6.5 \mathrm{~nm}$ and their depth with respect to the original silicon surface $6 \pm 1 \mathrm{~nm}$. Figure reproduced with permission from ref. ${ }^{41}$, Springer Nature.

reported. Various surfaces have been structured in that way, among them polymers $^{32,34,35}$, glass ${ }^{40,43}$, and also thin metal films $\mathrm{s}^{36,43}$ and silicon membranes ${ }^{46}$. Often femtosecond lasers have been used for the structuring process, as in Fig. 13, where the holes are then the result of a nano-ablation process. However, longer pulse lengths are also possible to use for structuring, as seen in the structured thin-film samples shown in Fig. 14, which were produced with a $\mathrm{KrF}$ laser with a pulse length of $23 \mathrm{~ns}$. In this case, the authors ascribe the holes to local melting and evaporation. Beyond the holes, also elevated structures, referred to as nanobumps and nanocones, can result from the irradiation with ns laser pulses due to trans-
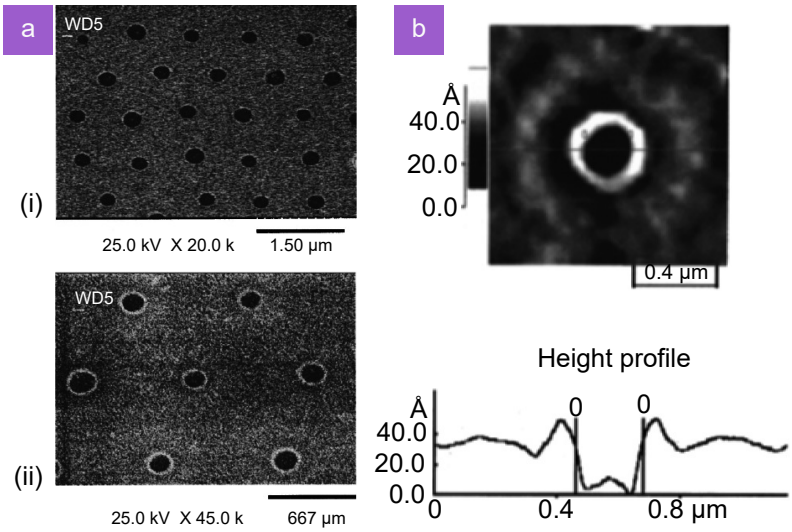

Fig. 14 | (a) (i) and (ii) SEM image of a periodic pit array in a $35 \mathrm{~nm}$ thick Al film on silicon, formed after the illumination of $0.95 \mu \mathrm{m} \mathrm{SiO}{ }_{2}$ particles by a single pulse with a fluence of $300 \mathrm{~mJ} / \mathrm{cm}^{2}(\mathrm{KrF}$ excimer laser, $\lambda=248 \mathrm{~nm}$, pulse width $23 \mathrm{~ns}$ ). (b) AFM image and depth profile of a pit. Figure reproduced with permission from ref. ${ }^{36}$, AIP Publishing. port processes in the substrate at such relatively long time scales s $^{38,4,47-49}$.

More complex periodic patterns can be generated by immersing the substrate together with the particle mask into liquids with various refractive indices ${ }^{50,51}$. The detailed structure of the patterns which are then formed upon laser irradiation depends on the difference of the refractive indices of the particles and the surrounding liquid medium.

A further development was reported by Guo et al. ${ }^{52}$, who investigated near-field parallel nanofabrication of arbitrary-shaped periodic patterns by using variable angles of incidence of the laser beam onto the nanosphere monolayer. The principle and a resulting pattern generated by a $\mathrm{KrF}$ laser $(15 \mathrm{~ns}, 248 \mathrm{~nm})$ in a $20 \mathrm{~nm}$ thick eutectic $\mathrm{Sb}_{70} \mathrm{~Tb}_{30}$ film coated on a polycarbonate substrate are shown in Fig. 15.
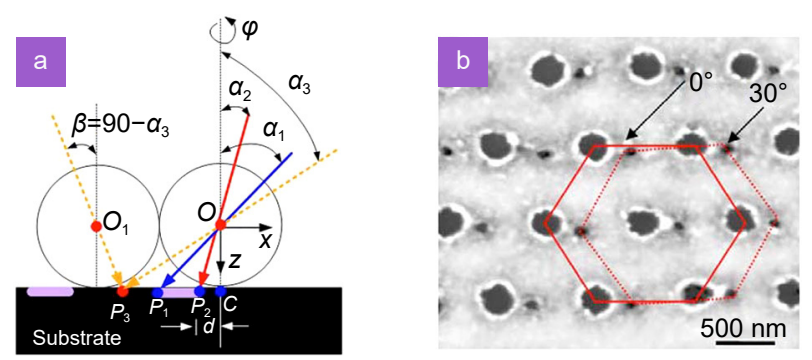

Fig. 15 | (a) Schematic diagram of the experimental configuration for direct laser writing of nanoline arrays on a $\mathrm{Sb}_{70} \mathrm{~Tb}_{30}$ substrate surface. (b) SEM image of two hexagonal nanodot arrays ablated by a single $\mathrm{KrF}$ laser pulse (pulse width $15 \mathrm{~ns}$ ) at an incident angle of $0^{\circ}$ (with a fluence of $6.5 \mathrm{~mJ} / \mathrm{cm}^{2}$ ) and $30^{\circ}$ (with a fluence of $1.0 \mathrm{~mJ} / \mathrm{cm}^{2}$ ), respectively. Figure reproduced with permission from ref. ${ }^{52}$, AIP Publishing.

Arbitrary patterning by means of a direct-write optical method using the near field of microspheres in optical traps has been described by the group of Arnold et al. ${ }^{53-55}$. An individual microsphere or also a microsphere array, held by optical tweezers, are used as near-field objectives in aqueous solution above a substrate which can be positioned by a translation stage. An AFM image of a hole created this way in a polycarbonate surface is shown in Fig. 16.

In Table 1, the experiments on optical near-field nanostructuring with dielectric micro- and nanospheres are summarized. The created nanostructures are named as in the corresponding publications, either "craters", "holes" or "dents" (if a depression is generated) or "bumps", "hillocks" or "cones" (for elevations). Most structures are $100 \mathrm{~nm}$ in size or larger; only structures below $100 \mathrm{~nm}$ 


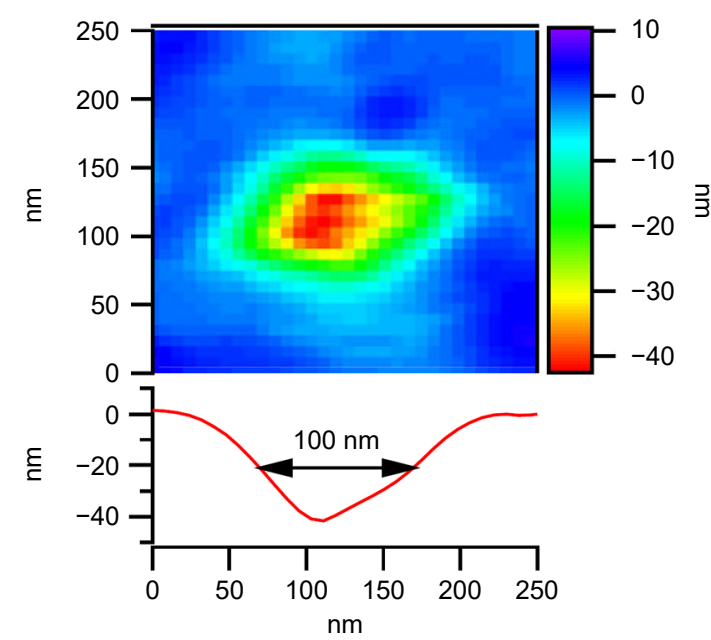

Fig. 16 | AFM scan of a hole created in polycarbonate by irradiation of a $760 \mathrm{~nm}$ bead with a $15 \mathrm{~ns}$ laser pulse $(\lambda=355 \mathrm{~nm})$ at $2.4 \mathrm{~J} / \mathrm{cm}^{2}$. A cross-profile of the central part is shown at the bottom. Figure reproduced with permission from ref. ${ }^{55}$, Springer Nature.

are mentioned in the column "special features". Only the most important parameters are listed here, for details the reader is referred to the original papers.

A few years after the first experiments on laser-induced ablation in the optical near field of micro- and nanospheres, the term "photonic nanojet" was coined for the tightly focused light distribution near the shadowside surface of the microlenses ${ }^{56}$. Many investigations have since then been carried out, where the effect of the strongly localized, high intensity light field of these nanojets has been used for applications in various fields in optics, electronics, and even biomedical research, well beyond laser ablation nanostructuring. Nonlinear optical phenomena have been exploited, e.g., in the optical absorption of $\mathrm{VO}_{2}$ and graphene oxide ${ }^{57-61}$. Reviews about photonic nanojets can be found, for example, in ref. ${ }^{62-64}$. The investigations described above and the results obtained for the nanostructuring of surfaces by means of the optical near field of small transparent spheres have also stimulated a development in the "reverse" direction, from near field to far field, namely an important improvement of optical microscopy: using silica microspheres with diameters between 2 and $9 \mu \mathrm{m}$, integrated in a classical optical microscope, the group of $M$. Hong has obtained a considerable extension of the optical resolution, and has imaged feature sizes as small as 23 $\mathrm{nm}^{65,66}$. Chen et al. have presented a recent review about this technique, including its potential and perspective ${ }^{67}$. A general overview over the near-field properties of high refractive index dielectric nanostructures and their use in functional nanostructures at optical frequencies has been given by Decker and Staude ${ }^{68}$.

\section{Optical near fields of plasmonic nanostructures}

While dielectric particles are already quite efficient for obtaining optical near fields on a scale distinctly smaller than the wavelength of light, an even stronger localization can be achieved with metallic nanostructures due to their plasmonic excitations. In scanning probe microscopy, this was used as a further advancement of the Scanning Near-Field Optical Microscope (SNOM): instead of a tiny aperture at the end of a glass fiber, one can also illuminate a fine metallic tip, with which - as an antenna - light can be coupled from the near field into the far field (and vice versa). This so-called aperture-less SNOM (aSNOM) has been developed towards a powerful microscopy technique with excellent resolution ${ }^{69-73}$.

One of the first efforts to exploit this antenna or "lightning rod" effect towards nanostructuring of surfaces was made already in 1996 by Jersch and Dickmann ${ }^{74}$. These authors illuminated the metallic tip of an STM with the pulses of a Nd:YAG laser (pulse width $\sim 10 \mathrm{~ns}$ ) and could generate in this way hole- or hillock-like structures in the range of several $\mathrm{nm}$. They called their technique FOLANT (Focusing of Laser Radiation in the Near Field of a Tip). Shortly afterwards it was demonstrated, however, these structures were not caused by the high electromagnetic field at the tip apex, as originally suggested, but resulted rather from the thermal expansion of the illuminated tip, which leads to a momentary mechanical contact with the substrate ${ }^{75-77}$. The appearance of the nanostructures was thus dominated by the adhesion properties of the tip/sample combination. Only a few years later, evidence was presented by the Singapore group that under certain conditions the near-field enhancement of ns pulses dominates over the mechanical modification of the substrate following from the thermal expansion of the tip ${ }^{78-80}$. Subsequently, Grigoropoulos and coworkers ${ }^{81,82}$, demonstrated opticalnear-field-induced structuring by an STP tip illuminated by fs laser pulses, where thermal effects play an inferior role compared to ns pulses .

\section{Triangular plasmonic nanostructures}

In order to disentangle structuring effects due to optical near fields from those originating from a pulsed mechanical contact between tip and sample, one can use proper 
Table 1 | Experiments on nanostructuring of various surfaces by means of local laser ablation or melting, using the optical near field of dielectric spheres.

\begin{tabular}{|c|c|c|c|c|c|c|c|}
\hline Year & $\begin{array}{l}\text { Structured } \\
\text { material }\end{array}$ & $\begin{array}{l}\text { Nanosphere size } \\
(\mathrm{nm}) \\
\text { and material }\end{array}$ & $\lambda(\mathrm{nm})$ & $\begin{array}{l}\text { Laser pulse } \\
\text { length }\end{array}$ & $\begin{array}{l}\text { Created } \\
\text { nano- } \\
\text { structures }\end{array}$ & Special feature & Reference \\
\hline 2000 & Si & $320-1700$ PS & $\begin{array}{l}583 \\
800\end{array}$ & $\begin{array}{l}30 \mathrm{ps} \\
150 \mathrm{fs}\end{array}$ & holes & & ref. $^{15}$ \\
\hline 2000 & $\mathrm{Si}$ & $500 \mathrm{SiO}_{2}$ & 248 & $23 \mathrm{~ns}$ & hillocks & multiple pulses & ref. ${ }^{26}$ \\
\hline 2001 & Si, BK7 glass & $320-1700$ PS & $\begin{array}{l}800 \\
800\end{array}$ & $\begin{array}{l}100 \mathrm{fs} \\
8 \mathrm{~ns}\end{array}$ & holes & $\begin{array}{l}\text { vertical and inclined } \\
\text { incidence }\end{array}$ & ref. ${ }^{28}$ \\
\hline 2001 & $\mathrm{Si}$ & $\begin{array}{l}320-1700 \\
\mathrm{SiO}_{2}, \mathrm{PS}\end{array}$ & $\begin{array}{l}800 \\
583 \\
532\end{array}$ & $\begin{array}{l}150 \mathrm{fs} \\
30 \mathrm{ps} \\
6.5 \mathrm{~ns}\end{array}$ & holes & & ref. ${ }^{24}$ \\
\hline 2001 & $\begin{array}{l}\text { urethane-urea } \\
\text { copolymer }\end{array}$ & 100-2000 PS & $\begin{array}{l}335 \\
532 \\
1064\end{array}$ & $\begin{array}{l}5 \mathrm{~ns} \\
5 \mathrm{~ns} \\
5 \mathrm{~ns}\end{array}$ & dents & particle array & ref. $^{32}$ \\
\hline 2002 & $\begin{array}{l}\mathrm{Si}, \mathrm{Ge}, \\
\text { BK7 glass }\end{array}$ & $320 / 800$ PS & $\begin{array}{l}800 \\
400 \\
800\end{array}$ & $\begin{array}{l}100 \mathrm{fs} \\
100 \mathrm{fs} \\
8 \mathrm{~ns}\end{array}$ & $\begin{array}{l}\text { holes } \\
\text { shallow pools }\end{array}$ & particle array & ref. $^{33}$ \\
\hline 2002 & Polyimide & $3000 \mathrm{SiO}_{2}$ & 248 & $28 \mathrm{~ns}$ & holes & particle array with spacer & ref. ${ }^{34}$ \\
\hline 2002 & PET & $5000 \mathrm{SiO}_{2}$ & 248 & $28 \mathrm{~ns}$ & holes & particle array with spacer & ref. $^{35}$ \\
\hline 2002 & Al film & $\begin{array}{l}140-1000 \\
\mathrm{SiO}_{2}, \mathrm{PS}\end{array}$ & 248 & $23 \mathrm{~ns}$ & holes & $\begin{array}{l}\text { particle array, } \\
\text { min hole size } 30 \mathrm{~nm}\end{array}$ & ref. ${ }^{36}$ \\
\hline 2003 & Si & $\begin{array}{l}560 \mathrm{PS} \\
640 \mathrm{SiO}_{2}\end{array}$ & $\begin{array}{l}248 \\
355\end{array}$ & $\begin{array}{l}10 \mathrm{~ns} \\
10 \mathrm{~ns}\end{array}$ & dents & particle array & ref. $^{37}$ \\
\hline 2003 & $\mathrm{Si}$ & 750 PS & $\begin{array}{l}532 \\
\text { pulse }\end{array}$ & $8 \mathrm{~ns}$ & cones & & ref. $^{47}$ \\
\hline 2003 & $\mathrm{Si}$ & $6000 \mathrm{SiO}_{2}$ & 248 & $28 \mathrm{~ns}$ & cones & particle array with spacer & ref. 48 \\
\hline 2003 & $\mathrm{Si}$ & $1300 \mathrm{PS}$ & 532 & $8 \mathrm{~ns}$ & cones & & ref. ${ }^{49}$ \\
\hline 2004 & GeSbTe film & PS & 248 & $23 \mathrm{~ns}$ & $\begin{array}{l}\text { arbitrary } \\
\text { patterns }\end{array}$ & $\begin{array}{l}\text { particle array, various } \\
\text { incidence angles }\end{array}$ & ref. ${ }^{131}$ \\
\hline 2005 & $\mathrm{Si}$ & 1000 PS & 248 & $23 \mathrm{~ns}$ & bumps & particle array & ref. ${ }^{38}$ \\
\hline 2005 & $\mathrm{Si}$ & 200-820 PS & 820 & $100 \mathrm{fs}$ & holes & $\begin{array}{l}\text { particle array, } \\
\min \text {. hole size } 67 \mathrm{~nm}\end{array}$ & ref. $^{39}$ \\
\hline 2006 & glass & $1000 \mathrm{SiO}_{2}$ & 800 & $100 \mathrm{fs}$ & craters & particle array & ref. ${ }^{40}$ \\
\hline 2007 & $\mathrm{Si}$ & $150 \mathrm{SiO}_{2}$ & $266-797$ & $300 \mathrm{fs}$ & holes & $\begin{array}{l}\text { particle array, } \\
\min \text {. hole size } 57 \mathrm{~nm}\end{array}$ & ref. ${ }^{41}$ \\
\hline 2007 & $\mathrm{Si}$ & $1000 \mathrm{PS}$ & 248 & $23 \mathrm{~ns}$ & bumps, holes & particle array & ref. 42 \\
\hline 2007 & $\mathrm{Sb}_{70} \mathrm{Te}_{30}$ film & $1000 \mathrm{SiO}_{2}$ & 248 & $15 \mathrm{~ns}$ & $\begin{array}{l}\text { arbitrary } \\
\text { patterns }\end{array}$ & $\begin{array}{l}\text { particle array, various } \\
\text { incidence angles }\end{array}$ & ref. $^{52}$ \\
\hline 2008 & Polyimide & $\begin{array}{l}490-3000 \mathrm{PS} \\
520 \mathrm{SiO}_{2}\end{array}$ & 355 & $15 \mathrm{~ns}$ & arb. patterns & optical trap & ref. $^{53}$ \\
\hline 2009 & Polyimide & 760-3000 PS & 355 & $15 \mathrm{~ns}$ & arb. patterns & optical trap array & ref. ${ }^{54}$ \\
\hline 2009 & Si membr. & $4300 \mathrm{SiO}_{2}$ & 532 & $10 \mathrm{~ns}$ & holes & through holes & ref. $^{46}$ \\
\hline 2009 & $\begin{array}{l}\text { glass, Au-, Ag-, Co } \\
\text { films }\end{array}$ & 700 PS & 532 & 400 ps & holes & & ref. $^{43}$ \\
\hline 2010 & Polycarbon. & $760 \mathrm{PS}$ & 355 & $15 \mathrm{~ns}$ & arb. patterns & optical trap & ref..$^{55}$ \\
\hline 2010 & $\mathrm{Si}$ & $5000 \mathrm{SiO}_{2}$ & 532 & $8 \mathrm{~ns}$ & $\begin{array}{l}\text { bumps, } \\
\text { craters }\end{array}$ & particle array & ref. ${ }^{132}$ \\
\hline 2010 & $\mathrm{Si}, \mathrm{SiO}_{2}$ & $200 \mathrm{TiO}_{2}$ & 400 & $100 \mathrm{fs}$ & holes & high index particles & ref. $^{133}$ \\
\hline 2010 & $\mathrm{Si}$ & $1500 \mathrm{SiO}_{2}$ & 248 & $23 \mathrm{~ns}$ & bumps & particle array & ref. ${ }^{44}$ \\
\hline 2013 & $\mathrm{Si}$ & $1000 \mathrm{SiO}_{2}$ & 193 & $25 \mathrm{~ns}$ & craters & array, multiple pulses & ref. ${ }^{45}$ \\
\hline 2015 & $\mathrm{Si}$ & $\begin{array}{l}195-1500 \\
\mathrm{SiO}_{2}, \text { melamine }\end{array}$ & 355 & $8 \mathrm{ps}$ & $\begin{array}{l}\text { complex } \\
\text { patterns }\end{array}$ & $\begin{array}{l}\text { particle array in organic } \\
\text { liquids }\end{array}$ & ref. $^{50}$ \\
\hline 2016 & $\mathrm{Si}$ & $\begin{array}{l}350-5000 \\
\mathrm{SiO}_{2}, \mathrm{PS}\end{array}$ & $\begin{array}{l}355 \\
532\end{array}$ & $\begin{array}{l}8 \mathrm{ps} \\
8 \mathrm{ps}\end{array}$ & $\begin{array}{l}\text { complex } \\
\text { patterns }\end{array}$ & $\begin{array}{l}\text { particle array in organic } \\
\text { liquids }\end{array}$ & ref. ${ }^{51}$ \\
\hline
\end{tabular}


nanoparticles deposited on the surface, instead of a scanning probe tip. Effects of thermal expansion are then considerably smaller. For the generation of locally tightly confined fields and large enhancement factors, metallic nanostructures with tips as sharp as possible are preferable. Such structures can be produced with the help of the self-organized compact monolayers of colloid spheres mentioned already above. Using these particle arrays as evaporation masks, flat triangular nanostructures can be prepared in a quite versatile way, where both the size and the thickness can be chosen over a wide range from several ten nanometers up to microns by using the proper colloid sphere size and evaporation conditions ${ }^{28-31}$. Also, the material of the evaporated nanostructures can be chosen at will. For most of the investigations to be discussed below the metal of choice was gold because of its superior plasmonic properties and resistance against corrosion. The main advantage of this "colloid lithography" is that, while relatively easy to be implemented, it allows one to produce periodic arrays of uniform nanostructures over areas as large as the colloid mask $\left(\mathrm{cm}^{2}\right)$ in a parallel fashion. Moreover, the triangles prepared in this way can have tip radii as small as $5 \mathrm{~nm}^{83}$, a scale which is difficult to achieve by conventional lithographic techniques. An example of such an array of nano-triangles is shown in Fig. 19. In addition to these colloid-generated triangles, many other plasmonic structures have been used for optical near-field studies, like spheres $^{84-86}$ and various kinds of rod-, bow-tie-, disc-like etc. nanoantennas, mostly prepared by electron- and ionbeam lithography. Some of them will be discussed further below.

The first time that plasmonic structures like the ones shown in Fig. 17 were used for nanoablation experiments was - to the best of our knowledge - reported in $2004^{83}$. As for the dielectric spheres in the last section, silicon was the substrate, and single femtosecond laser pulses served as light source. The intensity of the pulse was adjusted to a value sufficiently low so that the parts of the substrate far away from the triangles were not affected. Figure 18 shows the result of such an experiment. The original gold structures seen in Fig. 18(a) were completely removed by the laser pulse (possible mechanisms are discussed by Huang et al. ${ }^{87}$ ), and the silicon substrate
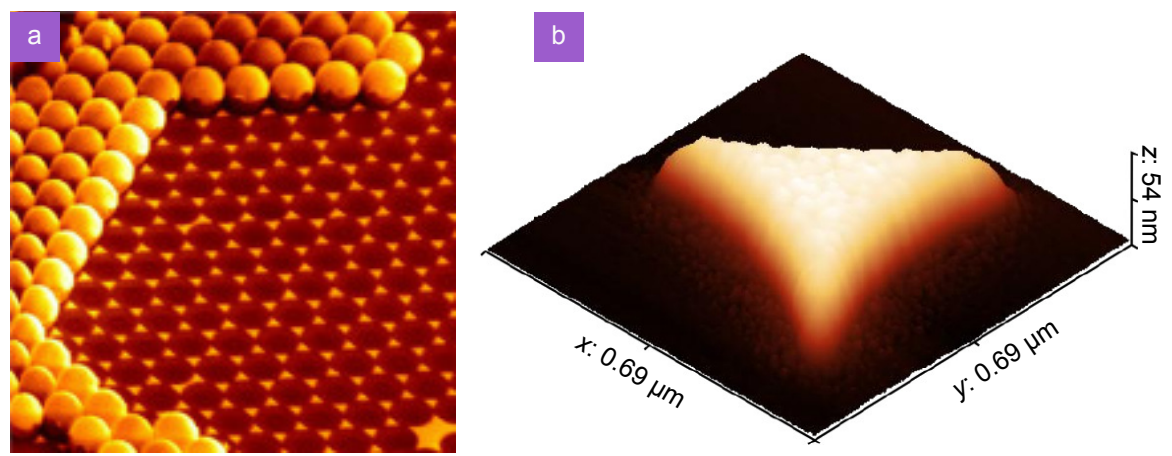

Fig. 17 | (a) SEM image of a regular array of triangular nanostructures prepared by colloid lithography. The colloid monolayer used as an evaporation mask has only been partly removed in this case. (b) AFM image of one triangle. Note that the scale in vertical direction is enlarged compared to the scale in plane. Figure reproduced with permission from ref. ${ }^{106}$, under the a Creative Commons Attribution License 2.0 .

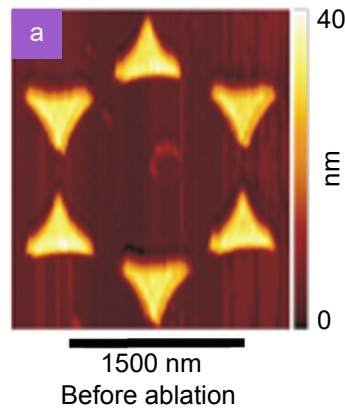

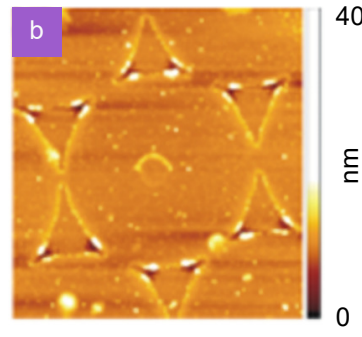

After ablation

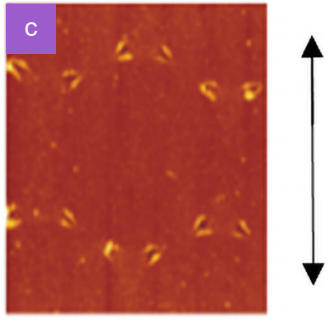

After etching Au

Fig. 18 | Gold triangles on silicon, side length 450 nm, 25 nm thick. (a) As prepared. (b) After irradiation with one laser pulse (laser source: Ti:sapphire laser, $\lambda=800 \mathrm{~nm}$, pulse width $150 \mathrm{fs}$ ). (c) After chemical removal of the gold. Light polarization vertical (indicated by the arrow on the right side). In (b), the former positions of the gold triangles are outlined as contours, formed by gold clusters which developed in the evaporation process through the colloid mask. Figure reproduced with permission from ref. ${ }^{83}$, AIP Publishing. 

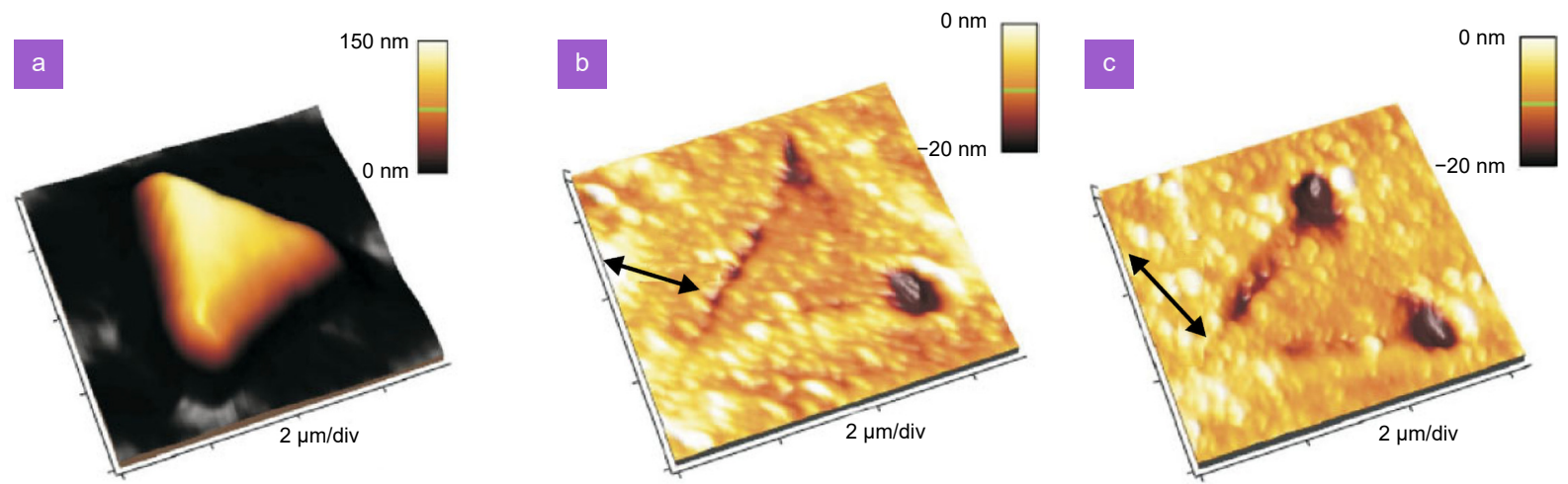

Fig. 19 | (a) AFM image of a single triangular gold nanoparticle on glass before laser treatment. (b) and (c) AFM images of the sample after illumination with a single linearly polarized laser pulse with a pulse duration of $35 \mathrm{fs}$. The black arrows indicate the polarization direction of the laser light (note: according to the authors, the scale in plane has to be corrected from $2 \mu \mathrm{m} / \mathrm{div}$ to $0.2 \mu \mathrm{m} / \mathrm{div}$ ). Figure reproduced with permission from ref. ${ }^{88}$, Springer Nature.

was intact mostly outside and also inside the triangle areas, except for some of the triangle corners, where ablation holes, discernible by the dark spots, are clearly visible. These holes are surrounded by elevated rims, as in parts of the ablation holes in Section Optical near fields of dielectric nanostructures. After chemical removal of the remaining gold clusters visible in Fig. 18(b), the holerim structure in the substrate becomes even more evident (Fig. 18(c)). It was found that the radius of curvature at the tips of the ablation holes can be as small as $5 \mathrm{~nm}$, which was also the tip radius of the original gold structure. Since the substrate will be ablated under and near the plasmonic particle only where the local intensity is high enough, it was argued in ref. ${ }^{83}$ that the resulting ablation pattern in the substrate thus represents a nonlinear "photograph" of the optical near field distribution of the nanoparticle under study.

The method works for the same kind of gold triangles not only on silicon, but also on smooth glass substrates, as demonstrated by Jamali et al. ${ }^{88}$. Figures 18 and 19 were a clear proof of the field enhancement at sharp tips of plasmonic structures. Moreover, they demonstrated that imaging optical near-field intensities by means of this method is possible not only for relatively broad, smeared-out distributions like simple dipolar patterns as in Fig. 10, but also for more complex near fields, and with a resolution of better than 1/50 of the incident light wavelength $\lambda=800 \mathrm{~nm}$. Compared to the aSNOM mentioned earlier and related techniques it has the advantage that no probe tip is required which might disturb the near-field distribution. It adds to other powerful methods for imaging optical near fields which do not rely on a probe tip, e.g. two-photon polymerization ${ }^{89-91}$, photochemical imaging ${ }^{92}$, phase change in certain chalcogen- ide films ${ }^{93,94}$, parabolic-mirror-based confocal microscopy $^{95}$, spatially resolved third harmonic emission ${ }^{96}$, and photoelectron microscopy (PEEM) ${ }^{97,98}$. Advantages of the nanoablation technique are the high resolution, relative simplicity, and that it can be applied under ambient conditions. In addition to ablation of silicon and glass substrates, also polymer coatings have since been used for electromagnetic-field-enhancement mapping around nanostructures ${ }^{99}$.

On closer inspection, the observed ablation pattern shown in Fig. 18 caused a puzzle: although it was expected that the near-field pattern of a metallic triangle, when illuminated with polarized light, is anisotropic and displays strong field enhancement at the triangle tips, the orientation of the field enhancement was surprising. One could have expected that field enhancement occurs mainly at the tips parallel to the polarization of the electric field, like in a dipole antenna. However, Fig. 18 shows that the intensity was largest for the tips aligned perpendicular to the electric field, and the tip pointing in the direction of the polarization did not bear a visible sign of field enhancement. (Another observation of "unexpected" polarization has more recently been reported by Metzger et al. ${ }^{100}$ for the second-harmonic near field of inversion-symmetric gold dipole nanoantennas. The authors report strong experimental evidence that the second-harmonic dipole field was predominantly oriented perpendicular to the dipole's long axis, although the excitation laser was polarized parallel to the dipoles.)

A hint for the origin of this apparent contradiction in the case of nanotriangles came from studying triangles of different size. For the smallest ones, with a side length of $160 \mathrm{~nm}$, the field enhancement was highest for the tip in the field direction, in agreement with naive expectation, 
and also with calculations ${ }^{83}$. For an intermediate size with $240 \mathrm{~nm}$ side length the field enhancement reached its maximum not at the tip, but rather in the middle of the edge perpendicular to the plane of polarization. These examples showed that plasmon resonances in metallic nanostructures can be quite complex because of the excitation of higher multipole modes, depending on size (and, as it turned out later, also on several other parameters, like the curvature of the triangle edges). A clue in that direction, however with much lower resolution, also came from far-field measurements on colloidmask-generated triangles using confocal scanning microscopy ${ }^{101}$. It was clear, therefore, that for a better understanding of the described near-field patterns a more thorough investigation, in particular also by means of simulations, was required.

In the course of time, various simulation techniques have been applied to model the near-field distribution of nanostructures, the most frequently used ones being the Discrete Dipole Approximation (DDA) and Finite Difference Time Domain (FDTD) simulations ${ }^{102}$. An example for a DDA simulation which models the plasmon
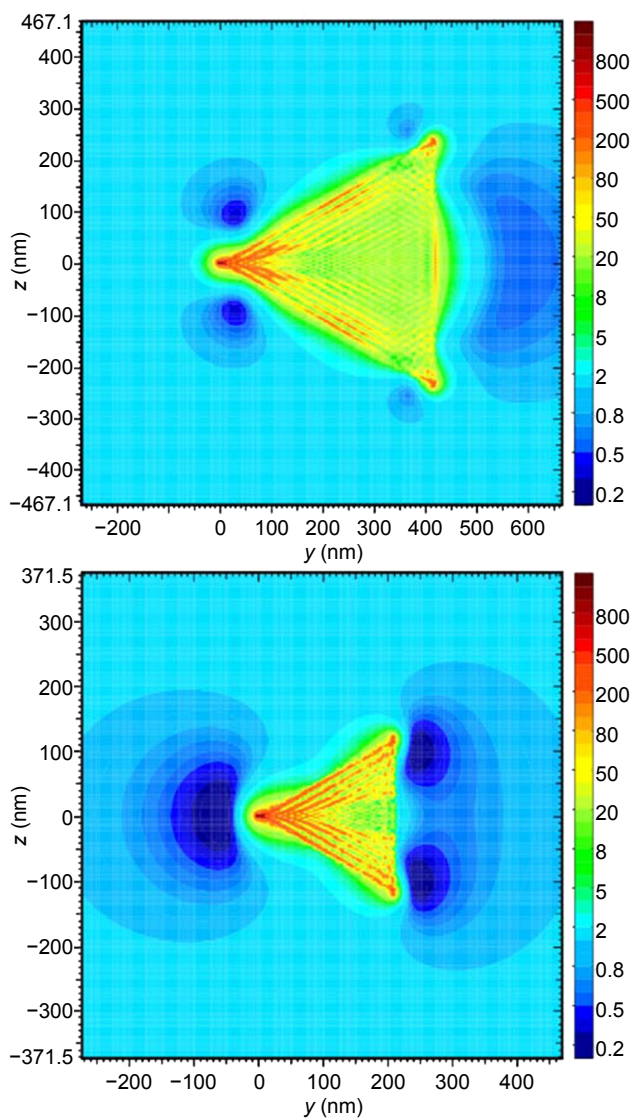

modes of single flat triangular structures is shown in Fig. 20 for two sizes, 480 and $240 \mathrm{~nm}$ side length, and two polarization directions of the incident beam with respect to the orientation of the triangle. For polarization along a triangle baseline one observes in the upper row two identical peaks of the field enhancement in the two corners along the polarization. For incident light polarized perpendicular to that direction, the intensity in one of the corners is about 6 times higher than in the other two corners. As one can see in the lower row of the figure, this behavior qualitatively does not change for the two sizes studied.

A comparison of Fig. 20 with experimental patterns like in Fig. 18 revealed that, while the calculated nearfield distributions for the small triangles are in agreement, the discrepancy for the larger ones persisted. It was then suggested that the disagreement might be caused by the periodic array of the particles in the experiment, which might give rise to interference effects, whereas the calculations had been performed for individual triangles. However, a subsequent experiment with isolated triangles did not yield a significantly different

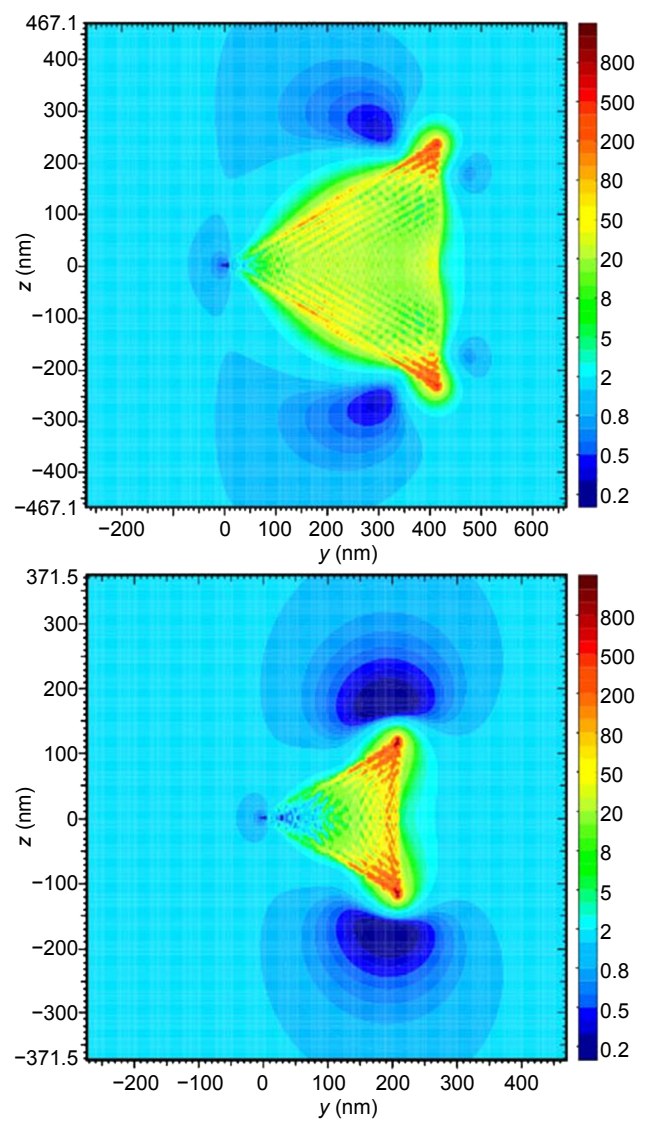

Fig. 20 | Field intensity distribution, as calculated by means of DDA, at the interface between a Si wafer and a $480 \mathrm{~nm}$ side length triangle (upper row) and a $240 \mathrm{~nm}$ side length triangle (lower row) of $30 \mathrm{~nm}$ height ( $\lambda=800 \mathrm{~nm}$, left side: polarization along $y$; right side: polarization along $z$ ). Figure reproduced with permission from ref. ${ }^{103}$, Springer Nature. 
near-field distribution, ruling out this explanation ${ }^{103}$. Another difference between the conditions in the simulation and the experiment was the actual shape of the triangles: whereas the calculations had been performed assuming triangles with straight edges, the experimental structures had slightly curved edges due to the preparation using nanospheres. Taking this feature into account eventually solved the riddle: Figure 21 presents simulation results (this time with FDTD simulation software by Lumerical Inc., which allows for a highly detailed 3-dimensional modeling of the plasmonic structure and its surroundings) for the near-field enhancement of small $(85 \mathrm{~nm})$ and large $(540 \mathrm{~nm})$ triangles with curved edges, and - to be even closer to the experiment - for hexagonal arrays of these structures ${ }^{104}$. Figure 22 shows for comparison the experimental nano-ablation patterns for the same sizes. The agreement in the patterns is now quite remarkable. This demonstrates that an unimportant detail at first sight can be essential for the proper simulation of plasmonic nanostructures. The FDTD calcula-
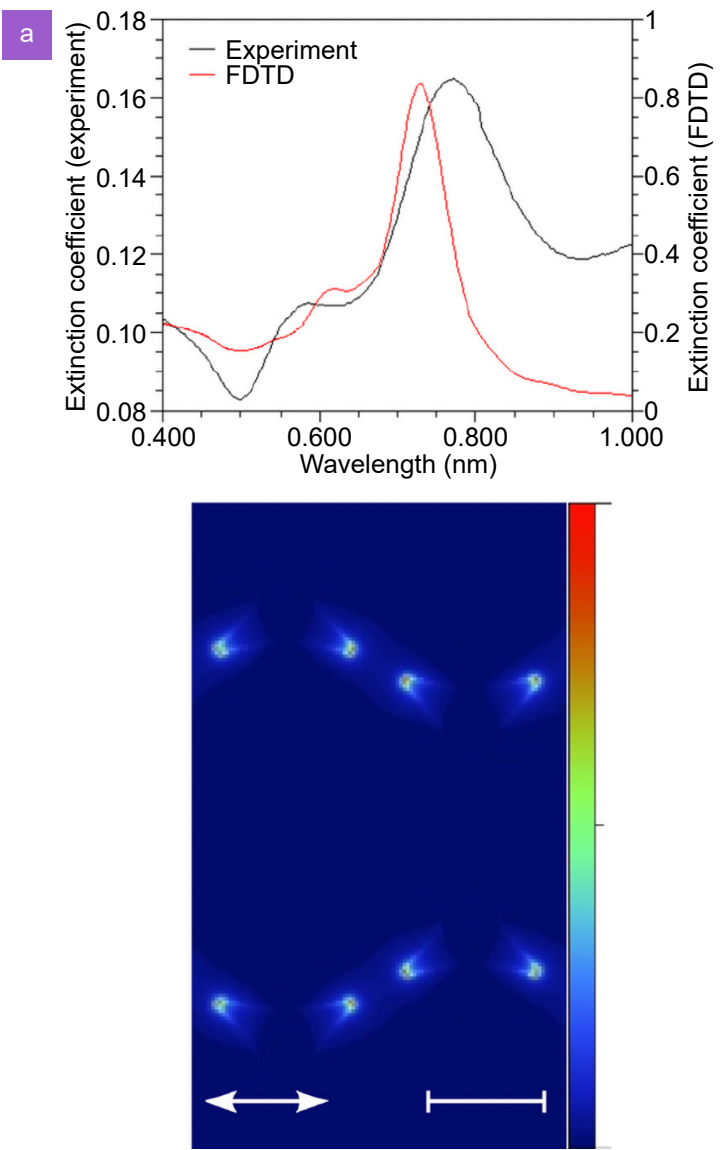

Fig. 21 | Measured and calculated absorption spectra for (a) $85 \mathrm{~nm}$ and (b) $540 \mathrm{~nm}$ nanotriangles on glass with the corresponding calculated scattered field intensities (normalized to the incoming field) for $800 \mathrm{~nm}$ irradiation on silicon. Small inset: calculated field distribution for a single $540 \mathrm{~nm}$ triangle. The double-headed arrows give the direction of the polarization of the incident laser light. Scale bars: $100 \mathrm{~nm}$ (a) and $300 \mathrm{~nm}$ (b). False color rulers: 0 to 255 (a) and 0 to 30 (b). Figure reproduced with permission from ref. ${ }^{104}$, Springer Nature. 

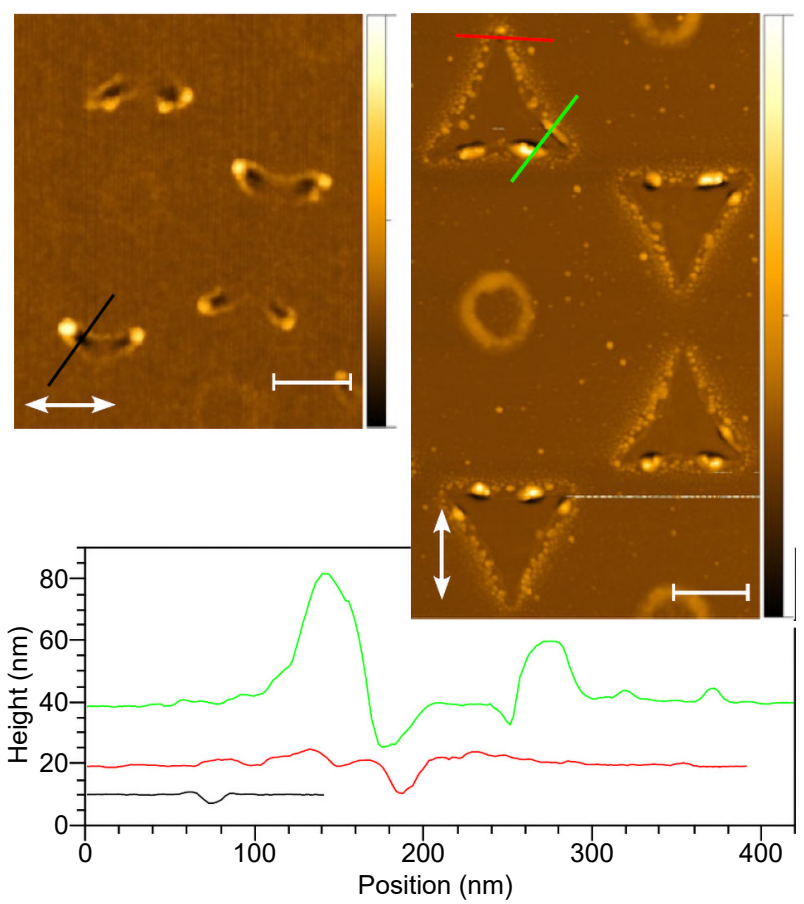

Fig. 22 | AFM images of the ablation pattern for nanotriangles with a side length of $85 \mathrm{~nm}$ (left) and $540 \mathrm{~nm}$ (right) on a silicon substrate (laser wavelength $800 \mathrm{~nm}$, pulse length $150 \mathrm{fs}$ ). The left sample had to be cleaned using the snow jet technique before the AFM scan, so the gold clusters around the contour of the original triangle positions are missing. The position of the height profile is depicted in the AFM image with a bar in the corresponding color. In the graph, the profiles are shown with an arbitrary offset. The doubleheaded arrows give the direction of the polarization of the incident laser light. Scale bars: $100 \mathrm{~nm}$ (left) and $300 \mathrm{~nm}$ (right). False color rulers: $0 \mathrm{~nm}$ to $10 \mathrm{~nm}$ (left) and $0 \mathrm{~nm}$ to $70 \mathrm{~nm}$ (right). Figure reproduced with permission from ref. ${ }^{104}$, Springer Nature.

calculations ${ }^{103}$. For DDA simulations, the importance of such highly detailed models has also been shown by Perassi $^{107}$.

The same method of nanolithographic mapping of near-field distributions via ablation has recently been applied by Nagy et al. ${ }^{108}$ in an investigation of near-field-induced femtosecond breakdown of gold triangles of about half the structure size shown in Fig. 23. Results for the near-field distribution of somewhat bigger triangular gold structures than in Fig. 23 have been obtained by Scheffler et al. ${ }^{109}$ using multiphoton photoemission electron microscopy (nP-PEEM), and good agreement with finite element simulations was also found in this case.

Whereas for the spatial distribution of the near field enhancement quite satisfactory agreement has been achieved between experiment and simulations, there is still some gap regarding the absolute values of the enhancement. Typically, the experimental enhancement factors are distinctly below the calculated ones, especially if details of the structure like roughness, tip radius and inclination of the edges are not properly taken into account. So far, there exist only few quantitative investigations; for some triangular structures, the experimentally determined enhancement (based on a method of evaluating the ablation thresholds with and without particles ${ }^{84,110}$ ) was by a factor of 2 to 5 below the simulation results ${ }^{106}$.

Like for the dielectric nano-spheres discussed in Section Optical near fields of dielectric nanostructures, also the optical near fields of plasmonic particles can be used for the purpose of nanostructuring surfaces, with a large variety of patterns that can be generated. Important parameters are the polarization, fluence and angle of incidence of the laser light, the size of the structures and their thickness, the refractive index of the substrate, etc. Two examples are shown in Figs. 25 and 26 for the case of gold triangles, which were used for structuring a glass surface applying the techniques described above ${ }^{111,112}$. With the profound understanding in simulating optical near fields that has been achieved, based on the mutual feedback between simulations and experiment, reliable predictions are now feasible how to tailor plasmonic nanostructures in order to obtain a desired pattern by means of laser nanoablation.

The near-field enhancement in metallic nanostructures due to plasmonic excitations can be used not only to pattern the surrounding material, but also to modify the plasmonic structures themselves. For this purpose, picosecond pulses are most suitable: they last long enough to allow local melting of the nanostructure in the regions of high near field, but are still so short that the thermal diffusion and hence melting does not extend over the whole structure, as is the case for ns pulses ${ }^{113}$. Figure 27 shows the result of irradiating an array of $\mathrm{Au}$ triangles with a single ps pulse; only two tips of each triangle are modified under the conditions of this experiment ${ }^{104}$. A comparison of the six different triangles in the inset reveals that even the details of the molten tips are nearly identical for triangles with the same orientation.

\section{Other plasmonic nanostructures}

The focus of this historical review is on the optical near fields of triangular gold structures and their nano-ablation patterns. There are, however, also many investigations of patterns generated by other plasmonic structures like metallic spheres and rods, which started 

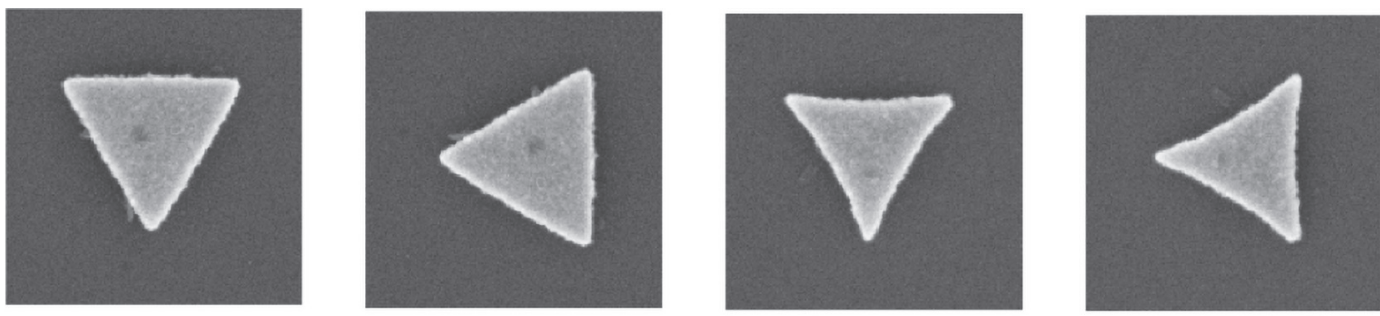

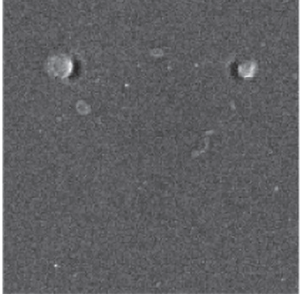

$175 \mathrm{~mJ} / \mathrm{cm}^{2}$

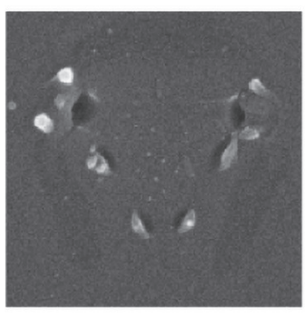

$250 \mathrm{~mJ} / \mathrm{cm}^{2}$

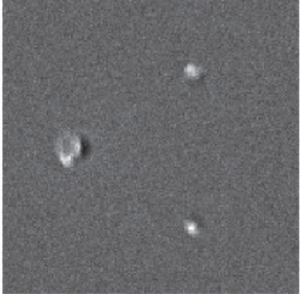

$190 \mathrm{~mJ} / \mathrm{cm}^{2}$

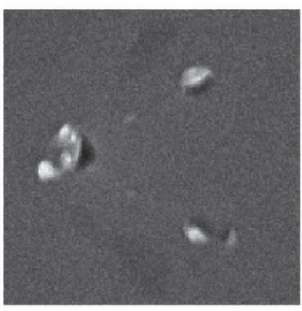

$230 \mathrm{~mJ} / \mathrm{cm}^{2}$

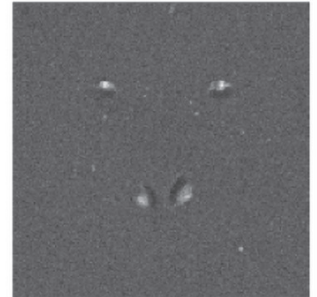

$200 \mathrm{~mJ} / \mathrm{cm}^{2}$

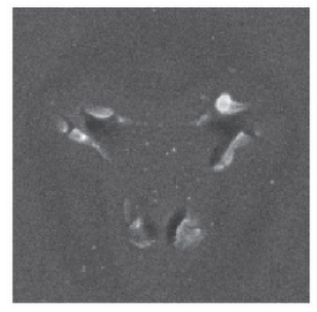

$280 \mathrm{~mJ} / \mathrm{cm}^{2}$

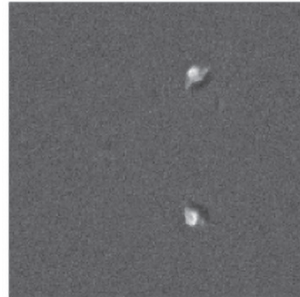

$200 \mathrm{~mJ} / \mathrm{cm}^{2}$

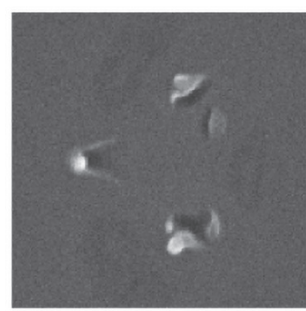

$260 \mathrm{~mJ} / \mathrm{cm}^{2}$

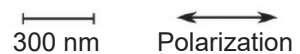

Fig. 23 | SEM micrographs of two different types of nanotriangles prepared by electron beam lithography, and their corresponding ablation patterns on a silicon substrate for two orientations with respect to the polarization of the incident light. The laser wavelength was $800 \mathrm{~nm}$, the pulse width $150 \mathrm{fs}$, and the local incident fluence is indicated below each frame. Figure reproduced with permission from ref. ${ }^{106}$, under a Creative Commons Attribution License 2.0.
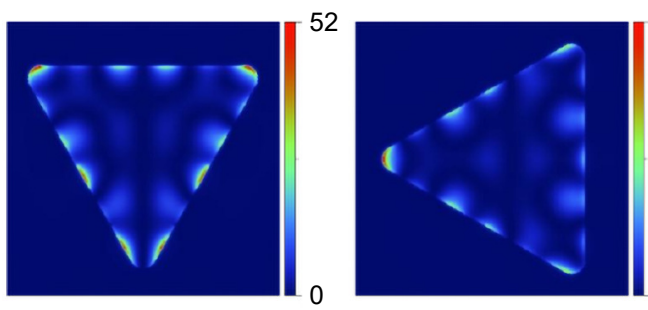
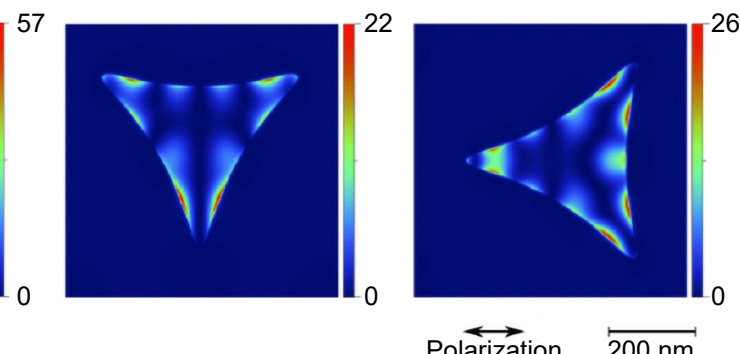

Fig. 24 | FDTD calculations for the structures presented in Fig. 23. The field intensity enhancement was extracted in a plane between the $\mathrm{SiO}_{2}$ layer (thickness $2.4 \mathrm{~nm}$ ) and the Si substrate below the triangle. The simulation volume was $3 \mu \mathrm{m} \times 3 \mu \mathrm{m} \times 6 \mu \mathrm{m}$ with "perfectly matched layer" boundary conditions. The meshing was set to automatic mode far from the triangle, and a manually refined mesh with a cell size of 2 nm $\times$ $2 \mathrm{~nm} \times 0.5 \mathrm{~nm}$ was added around the particle. Figure reproduced with permission from ref. ${ }^{106}$, under a Creative Commons Attribution License 2.0 .

somewhat later. Overviews over plasmonic near fields, their imaging and applications for nanoprocessing have been given in the last decade in a number of review articles, see, e.g. ${ }^{114-119}$.

An early investigation of the optical near fields and nano-hole fabrication by spherical gold particles with sizes of 40, 80 and $200 \mathrm{~nm}$ was presented in 2006 by Nedyalkov et al. ${ }^{84,120}$. These authors pointed out that the observed nano-hole profiles in the fluence region below the ablation threshold of bulk Si resembled the laser in- tensity distribution on the substrate surface. When linearly polarized laser radiation was used, the holes were found to exhibit an elongated shape in the direction of polarization, similar to the case of small dielectric spheres, but with a much higher enhancement; for 200 $\mathrm{nm}$ spheres, enhancement factors of 26 and 7.5 were found in simulation and experiment, respectively. The hole diameters were between several ten and hundred $\mathrm{nm}$, the hole depths ranged from a few to several ten $\mathrm{nm}$. A similar study was carried out about a year later by 

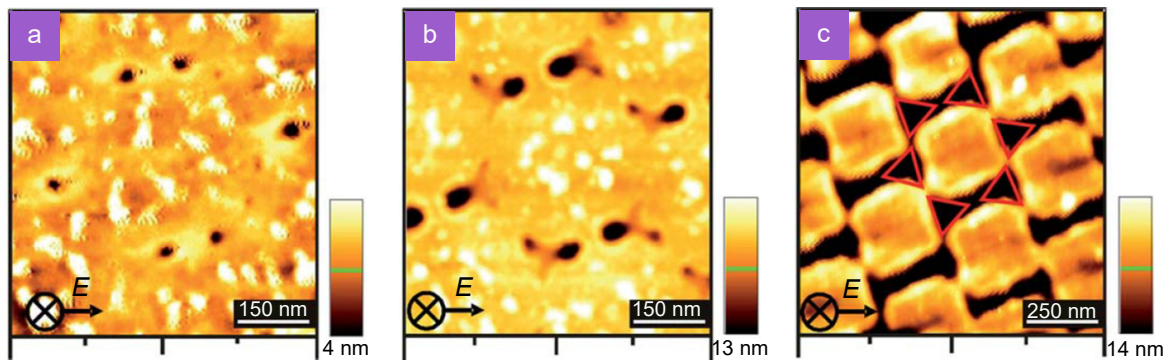

Fig. 25 | AFM images of nanopatterns generated on a fused silica substrate with a single pulse of a Ti:saphhire laser $(\lambda=790 \mathrm{~nm}, \mathrm{FWHM} 35 \mathrm{fs})$ in a region of low (a), medium (b), and high (c) laser fluence. The applied pulse energy was $E=0.16 \mathrm{~mJ}$. The red triangles (right image) indicate the original position of the triangular NPs on the substrate prior to irradiation. For clarity reasons, the red triangles have been drawn larger than the original NPs, which, in fact, have a tip to tip distance of approximately $100 \mathrm{~nm}$. The black arrows indicate the polarization direction of the incoming laser light. Figure reproduced with permission from ref. ${ }^{112}$, The Royal Society of Chemistry (https://doi.org/10.1039/c0jm03829f).
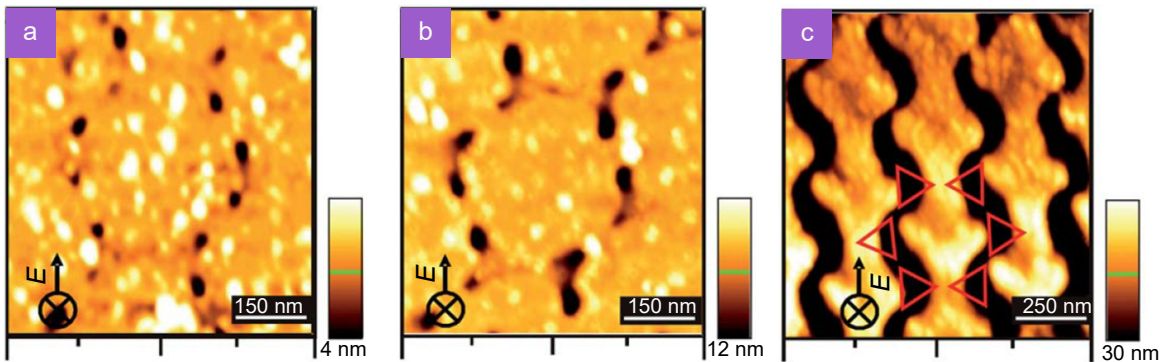

Fig. 26 | AFM images of nanopatterns generated like in Fig. 25, but with a different laser polarization, in a region of low (a), medium (b), and high (c) laser fluence. The applied pulse energy was $E=3.8 \mathrm{~mJ}$. The red triangles (right image) indicate the original position of the triangular NPs on the substrate prior to irradiation. Again, for clarity reasons, the red triangles have been drawn larger than the original NPs, which, in fact, have a tip to tip distance of approximately $100 \mathrm{~nm}$. The black arrow indicates the polarization direction of the laser light. Figure reproduced with permission from ref. ${ }^{112}$, The Royal Society of Chemistry (https://doi.org/10.1039/c0jm03829f).

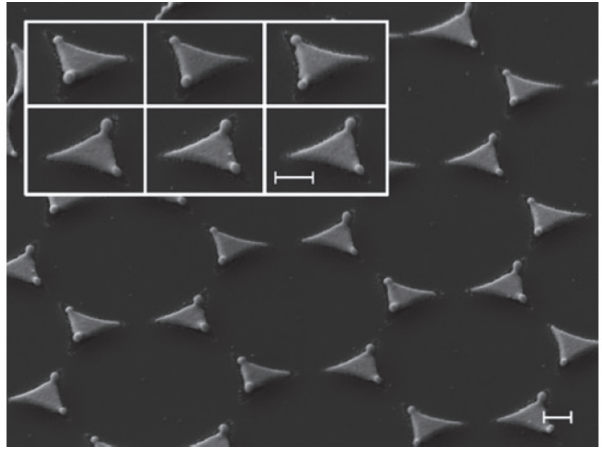

Fig. 27 | SEM image of modified nanotriangles (produced with $1740 \mathrm{~nm}$ colloids) after irradiation with a single ps laser pulse ( $\lambda=\mathbf{8 0 0 ~} \mathbf{n m}$, FWHM $300 \mathrm{ps}$ ). Scale bars: $300 \mathrm{~nm}$, laser polarization in $x$ - direction. Figure reproduced with permission from ref. ${ }^{104}$, Springer Nature.

Eversole et al. ${ }^{110}$ (Fig. 28), who investigated also the difference between perpendicular and inclined incidence of s- and p-polarized light. They found that the measured field-enhancement values agreed well with the calculated ones, and in some case even a slight increase above the theoretical value was observed.

In the same year, Nedyalkov et al. studied the nanoablation by gold spheres on a different substrate, namely a platinum film ${ }^{85}$. Since the spheres partly formed 2-dimensional aggregates, similar to dielectric colloid spheres, these authors obtained also results for such arrays and checked the influence of the interparticle distance on the field enhancement. It turned out that for these metallic spheres - in contrast to dielectric ones edge particles display the strongest field enhancement. Again, the experimental results confirmed the theoretical findings and demonstrated that the produced near fields can lead to a permanent substrate modification. Somewhat later, Hashimoto et al. ${ }^{121,122}$ observed the formation of craters of less than $10 \mathrm{~nm}$ diameter in borosilicate glass substrates upon irradiating $40 \mathrm{~nm}$ gold nanoparticles with a nanosecond pulsed laser beam. Imamova et al. ${ }^{86}$ reported the preparation of metallic nanoparticle arrays by laser annealing and dewetting of thin $\mathrm{Au}$ and $\mathrm{Ag}$ films on $\mathrm{SiO}_{2}$ substrates and obtained also images of the near fields of the such-produced particles by the nano-ablation method.

In addition to metallic spheres, also metal nanorods have been used for optical near field and laser ablation studies. Using Au nanorods on a Si substrate, Harrison et al. investigated the role of near-field enhancement for 

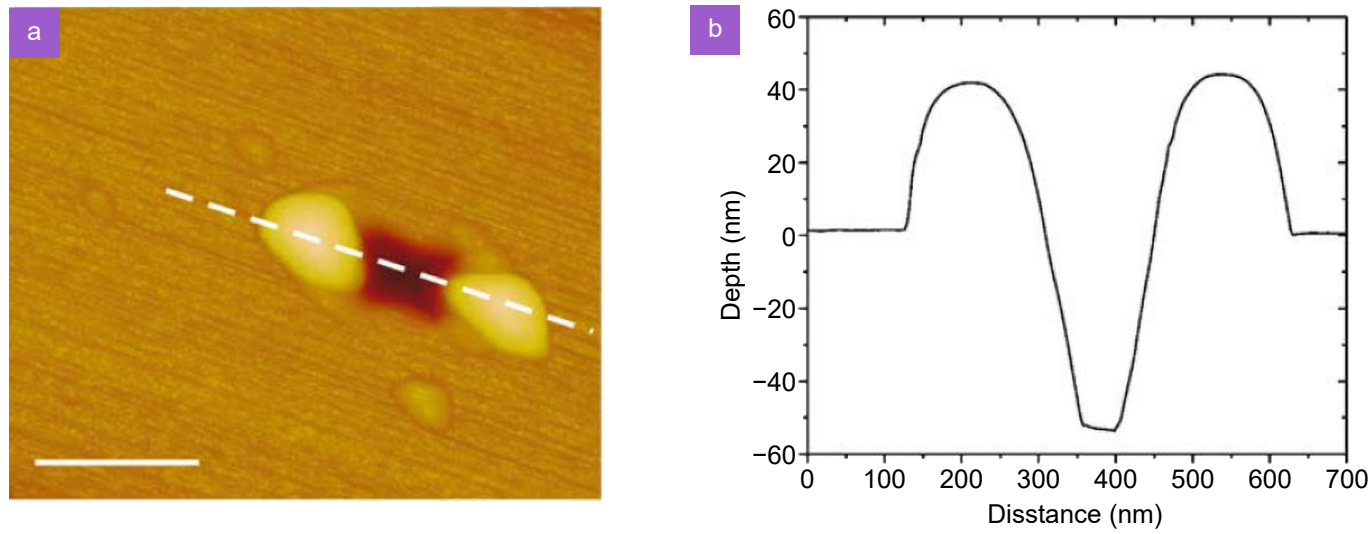

Fig. 28 | AFM images of nanocraters ablated by $150 \mathrm{~nm}$ gold nanoparticles on silicon (100) and corresponding cross section as found along the white dotted line. The laser pulse width was $220 \mathrm{fs}$, the wavelength $780 \mathrm{~nm}$ and the fluence $128 \mathrm{~mJ} / \mathrm{cm}^{2}$; the light was s-polarized at $45^{\circ}$ incident angle. The scale bar is $200 \mathrm{~nm}$. Figure reproduced with permission from ref. ${ }^{110}$, Springer Nature.

such structures in plasmonic laser nano-ablation ${ }^{123,124}$. Near the ablation threshold, features as small as $22 \times 66$ $\mathrm{nm}$, given by the size of the gold particles, were found as "photo-imprints" (Fig. 29).

From their results Harrison et al. concluded that the rod-shaped ablation structures matched the enhancement patterns of the Poynting vector magnitude rather than the electric field $|\boldsymbol{E}|^{2}$ enhancement pattern, as used in most previous work. This result was disputed by the group of Meunier ${ }^{125}$ who showed that in their experiment the data matched the $|\boldsymbol{E}|^{2}$ pattern. The latter result was also found by Kolloch to hold for his ablation patterns of triangular gold structures ${ }^{105}$, as shown in Fig. 30.

Meunier's group also addressed the question what eventually limits the size of the ablation features in $\mathrm{Si}$ substrates $^{126}$. Again, gold nanorods were used as
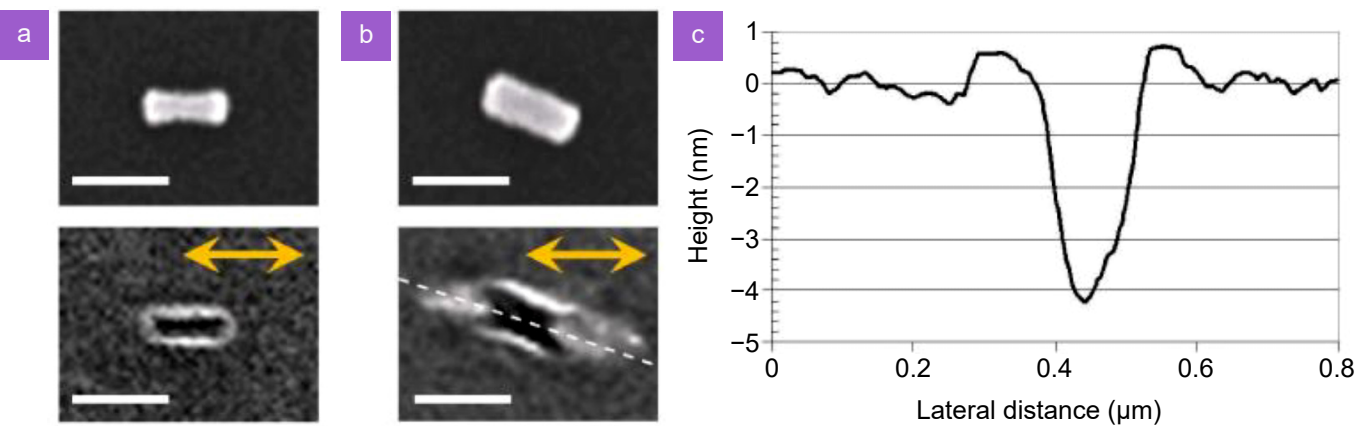

Fig. 29 | Nanoscale ablation site and depth profile: SEM images of the nanorods before and after laser irradiation at a local effective fluence of (a) $54 \mathrm{~mJ} / \mathrm{cm}^{2}$, right at the ablation threshold, and (b) $218 \mathrm{~mJ} / \mathrm{cm}^{2}$. The scale bars correspond to $75 \mathrm{~nm}$ and the yellow arrows indicate the incident polarization. (c) The depth profile of the ablation site shown in (b), along the long axis shown with the dotted line as obtained using AFM. Note the different scales for the horizontal and vertical axes in (c). Figure with permission from ref. ${ }^{129}$, The Optical Society.
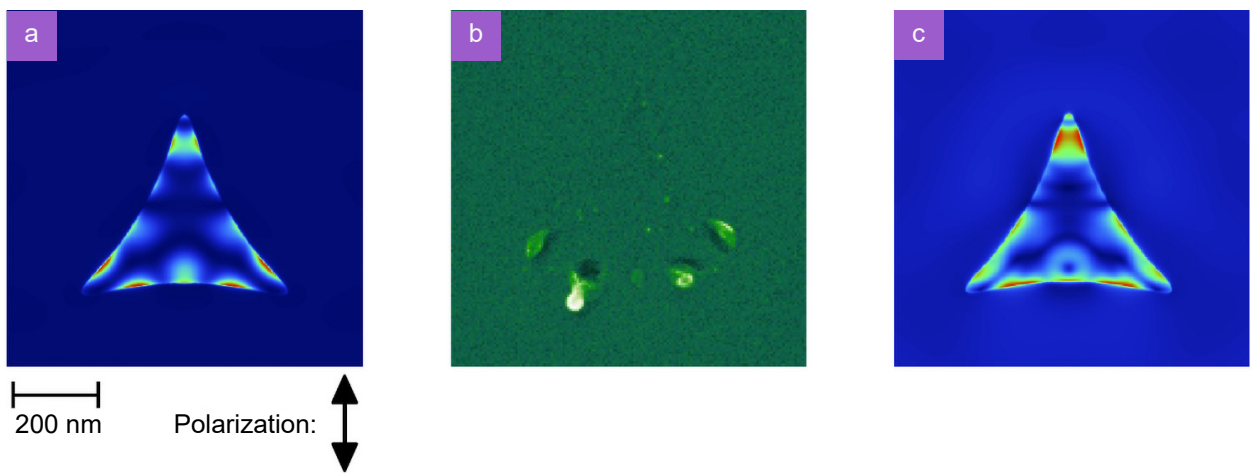

Fig. $30 \mid$ Simulations of the near-field enhancement $|\boldsymbol{E}|^{2}(\mathrm{a})$ and of the norm of the Poynting vector distribution $|\boldsymbol{P}|$ (c) for a round-edged triangle as prepared by e-beam lithography. The middle (b) shows the experimental ablation pattern. A comparison reveals that the experimental pattern agrees much better with (a) than with (c). Figure reproduced from ref. ${ }^{105}$. 
plasmonic particles. The observed hole shape seemed inconsistent with the calculated field distribution, but using a carrier diffusion-based model both the shape and the depth of the nanoholes could be explained. According to this model, charge carriers created as electron-hole pairs in the nanostructure's enhanced near field diffuse before they transfer their energy to the Si lattice, producing ablation. As the authors point out, the strong localization of the energy absorption, which can be distinctly smaller than the carriers' diffusion length, is the key difference between nano-ablation and conventional laser ablation $^{127,128}$ of silicon. A similar argument has been put forth by Kolloch ${ }^{105,106}$ based on the size of near-field ablated nanoholes at the apex of an optical bow-tie antenna. Carrier diffusion will thus limit the achievable minimum ablation feature size in silicon to the so far observed scale of about $10 \mathrm{~nm}^{83,84}$ even if plasmonic structures with more tightly confined near fields could be prepared. With other materials, however, where this broadening process is absent, even smaller features might be accessible.

An overview over the nanostructures generated by plasmonic near fields, as discussed in this chapter, is given in Table 2. As in Table 1, only the most important

Table 2 | Experiments on nanostructuring of various surfaces by means of laser ablation, using the optical near field of plasmonic structures.

\begin{tabular}{|c|c|c|c|c|c|c|c|c|}
\hline Year & $\begin{array}{l}\text { Structured } \\
\text { material }\end{array}$ & $\begin{array}{l}\text { Plasmonic } \\
\text { structure: } \\
\text { shape and } \\
\text { size }(\mathrm{nm})\end{array}$ & $\begin{array}{l}\text { Plasmonic } \\
\text { material }\end{array}$ & $\lambda(\mathrm{nm})$ & $\begin{array}{l}\text { Laser pulse } \\
\text { length }\end{array}$ & $\begin{array}{l}\text { Created nano- } \\
\text { structures }\end{array}$ & Special feature & Reference \\
\hline 2004 & $\mathrm{Si}$ & $\begin{array}{l}\text { triangles side length } \\
160,240,450\end{array}$ & $\mathrm{Au}$ & 800 & $150 \mathrm{fs}$ & $\begin{array}{l}\text { holes, min. diam. } \\
10 \mathrm{~nm}\end{array}$ & particle array & ref. $^{83}$ \\
\hline 2006 & $\mathrm{Si}$ & $\begin{array}{l}\text { spheres, dia. } \\
40,80,200\end{array}$ & $\mathrm{Au}$ & 820 & $100 \mathrm{fs}$ & $\begin{array}{l}\text { holes, min. diam. } \\
40 \mathrm{~nm}\end{array}$ & & ref. $^{84}$ \\
\hline 2007 & $\mathrm{Pt}$ & spheres, dia. 200 & $\mathrm{Au}$ & 800 & $100 \mathrm{fs}$ & holes & particle array & ref. ${ }^{85}$ \\
\hline 2007 & $\mathrm{Si}$ & spheres, dia. 150 & $\mathrm{Au}$ & 780 & $220 \mathrm{fs}$ & $\begin{array}{l}\text { craters, depth } \\
20-100 \mathrm{~nm}\end{array}$ & $\begin{array}{l}\text { vertical and } \\
\text { inclined incidence }\end{array}$ & ref. ${ }^{110}$ \\
\hline 2007 & $\mathrm{Si}$ & $\begin{array}{l}\text { triangles, side length } \\
240,480\end{array}$ & $\mathrm{Au}$ & 800 & $150 \mathrm{fs}$ & holes & particle array & ref. ${ }^{103}$ \\
\hline 2009 & fused quartz & $\begin{array}{l}\text { triangles, } \\
\text { side length } 74\end{array}$ & $\mathrm{Au}$ & 790 & $35 \mathrm{fs}$ & $\begin{array}{l}\text { channels, } \\
\text { width } 96 \mathrm{~nm}\end{array}$ & particle array & ref. ${ }^{111}$ \\
\hline 2009 & glass & $\begin{array}{l}\text { spheres, dia. } \\
40\end{array}$ & $\mathrm{Au}$ & 532 & $6 \mathrm{~ns}$ & $\begin{array}{l}\text { craters, } \\
\text { width }<10 \mathrm{~nm}\end{array}$ & multiple laser pulses & ref. $^{121}$ \\
\hline 2010 & $\mathrm{Si}$ & $\begin{array}{l}\text { rod, } \\
22 \times 66\end{array}$ & $\mathrm{Au}$ & 780 & $184 \mathrm{fs}$ & $\begin{array}{l}\text { rectang. hole, } \\
\text { depth } 4 \mathrm{~nm}\end{array}$ & & ref. $^{123}$ \\
\hline 2011 & glass & spheres, dia 40-50 & $\mathrm{Au}$ & 532 & $6 \mathrm{~ns}$ & craters & & ref. $^{122}$ \\
\hline 2011 & $\mathrm{Si}$ & $\begin{array}{l}\text { rod, } \\
25 \times 84\end{array}$ & $\mathrm{Au}$ & 800 & $120 \mathrm{fs}$ & $\begin{array}{l}\text { double crater, } \\
\text { depth } 3 \mathrm{~nm}\end{array}$ & & ref. $^{125}$ \\
\hline 2011 & fused quartz & $\begin{array}{l}\text { triangles, } \\
\text { side length } 140\end{array}$ & $\mathrm{Au}$ & 790 & $35 \mathrm{fs}$ & $\begin{array}{l}\text { holes, } \\
\text { width } 23 \mathrm{~nm} \\
\text { grooves, } \\
\text { width } 44 \mathrm{~nm}\end{array}$ & particle array & ref. ${ }^{112}$ \\
\hline 2011 & $\mathrm{Si}$ & $\begin{array}{l}\text { triangles, } \\
\text { side length } \\
85,540\end{array}$ & $\mathrm{Au}$ & $\begin{array}{l}800 \\
800\end{array}$ & $\begin{array}{l}150 \mathrm{fs} \\
300 \mathrm{ps}\end{array}$ & $\begin{array}{l}\text { near field image } \\
\text { craters, min. width } \\
<10 \mathrm{~nm}\end{array}$ & particle array & ref. ${ }^{104}$ \\
\hline 2013 & $\mathrm{Si}$ & $\begin{array}{l}\text { triangles, } \\
\text { bow-tie, } \\
530\end{array}$ & $\mathrm{Au}$ & $\begin{array}{l}800 \\
800\end{array}$ & $\begin{array}{l}150 \mathrm{fs} \\
300 \mathrm{ps}\end{array}$ & $\begin{array}{l}\text { near field image } \\
\text { craters }\end{array}$ & particle array & ref. ${ }^{106}$ \\
\hline 2013 & fused quartz & $\begin{array}{l}\text { triangles, } \\
\text { side length } \\
100,320\end{array}$ & $\mathrm{Au}$ & 790 & $35 \mathrm{fs}$ & $\begin{array}{l}\text { holes, } \\
\text { dia. } 100 \mathrm{~nm}\end{array}$ & particle array & ref. $^{88}$ \\
\hline 2013 & PMMA & $\begin{array}{l}\text { squares side length } \\
450 \mathrm{~nm}\end{array}$ & $\mathrm{Au}$ & 790 & $100 \mathrm{fs}$ & ablation spots & particle array & ref. ${ }^{99}$ \\
\hline 2020 & $\begin{array}{l}\text { fused silica, with } \\
\text { ITO film on top }\end{array}$ & $\begin{array}{l}\text { triangles } \\
154 \times 164\end{array}$ & $\mathrm{Au}$ & 803 & $40 \mathrm{fs}$ & $\begin{array}{l}\text { near field image } \\
\text { craters }\end{array}$ & $\begin{array}{l}\text { particle array, } \\
\text { multiple laser pulses }\end{array}$ & ref. $^{108}$ \\
\hline
\end{tabular}


parameters are mentioned here, for details the reader is referred to the original papers.

\section{Conclusions}

It was the goal of this historical review to give an impression of the early investigations of optical near-field structuring, dating back about 20 years, out of which the more recent applications developed. This history is an example that often new methods emerge out of studies with a quite different perspective. The starting point of near-field nanopatterning was laser cleaning in the 1990s. There the aim was just the opposite, namely to remove contaminating nanoparticles from delicate surfaces without any modification of the substrate. Once it was clear, however, that dry laser cleaning - in spite of its at-first-sight gentle and contactless removal concept gave rise to local ablation in the substrate, this new possibility of nanostructuring was quickly adopted and studied by a number of groups worldwide. In the beginning, the focus was on structuring surfaces by means of the near field of transparent nanospheres, which offer the additional advantage that they easily self-organize in large regular arrays and thus enable one to pattern surfaces with thousands or millions of nanoholes in a onestep process with just one laser pulse on many substrates of choice, including metals, semiconductors and dielectrics. With the methods being refined in the course of time, structures more complex than just periodically arranged round holes could be generated with the near fields of these nanospheres, and in addition also chemical etching and other nanoscale surface modifications were achieved, which are interesting for chemical, biological and medical purposes.

Metallic (that is plasmonic) structures can enhance electromagnetic fields even more and to even smaller scales than dielectric ones. This has been demonstrated not only for nanostructuring with spheres, but also with less symmetric objects such as triangles, rods, etc. Since in the field of plasmonic applications the detailed distribution of the optical near fields is of paramount importance, many efforts have been directed towards imaging these near fields. Nanoablation has in this context proven as a convenient method with high resolution and without the often disturbing influence of a probe tip, as it is necessary for some of the other imaging techniques. The in-depth comparison of the experimental ablation patterns with simulations have revealed excellent agreement in the spatial distribution of the near fields, provided all the essential details of the plasmonic object are taken into account in the simulations. It has also been shown, however, that the calculated enhancement factors are typically somewhat larger than the experimental ones, yet of the same magnitude. From such knowledge one can draw conclusions how trustworthy simulations of more applied structures like optical antennas or plasmonic tweezers ref. ${ }^{129,130}$ can be.

\section{References}

1. Gargini P. The International Technology Roadmap for Semiconductors (ITRS): past, present and future. In 22nd Annual Gallium Arsenide Integrated Circuit (GaAs IC) Symposium 3-5 (IEEE, 2000); http://doi.org/10.1109/GAAS.2000.906261.

2. Zapka W, Ziemlich W, Tam AC. Efficient pulsed laser removal of $0.2 \mu \mathrm{m}$ sized particles from a solid surface. Appl Phys Lett 58, 2217-2219 (1991).

3. Tam AC, Leung WP, Zapka W, Ziemlich W. Laser-cleaning techniques for removal of surface particulates. J Appl Phys 71, 3515-3523 (1992).

4. Imen K, Lee SJ, Allen SD. Laser-assisted micron scale particle removal. Appl Phys Lett 58, 203-205 (1991).

5. Yavas O, Leiderer P, Park HK, Grigoropoulos CP, Poon CC et al. Optical reflectance and scattering studies of nucleation and growth of bubbles at a liquid-solid interface induced by pulsed laser heating. Phys Rev Lett 70, 1830-1833 (1993).

6. Yavas O, Leiderer P, Park HK, Grigoropoulos CP, Poon CC et al. Enhanced acoustic cavitation following laser-induced bubble formation: long-term memory effect. Phys Rev Lett $\mathbf{7 2}$, 2021-2024 (1994).

7. Yavas $\mathrm{O}$, Leiderer $\mathrm{P}$, Park HK, Grigoropoulos $\mathrm{CP}$, Poon $\mathrm{CC}$ et al. Optical and acoustic study of nucleation and growth of bubbles at a liquid-solid interface induced by nanosecondpulsed-laser heating. Appl Phys A 58, 407-415 (1994).

8. Yavas $\mathrm{O}$, Schilling $\mathrm{A}$, Bischof $\mathrm{J}$, Boneberg $\mathrm{J}$, Leiderer $\mathrm{P}$. Bubble nucleation and pressure generation during laser cleaning of surfaces. Appl Phys A 64, 331-339 (1997).

9. Dobler V, Oltra R, Boquillon JP, Mosbacher M, Boneberg J et al. Surface acceleration during dry laser cleaning of silicon. Appl Phys A 69, S335-S337 (1999).

10. Arnold N, Schrems G, Mühlberger T, Bertsch M, Mosbacher M et al. Dynamic Particle removal by nanosecond dry laser cleaning: theory. Proc SPIE 4426, 340-346 (2002).

11. Oltra R, Arenholz E, Leiderer $P$, Kautek W, Fotakis $C$ et al. Modeling and diagnostics of pulsed laser-solid interactions: Applications to laser cleaning. Proc SPIE 3885, 499-508 (2000).

12. Mosbacher M, Chaoui N, Siegel J, Dobler V, Solis $\mathrm{J}$ et al. A comparison of NS and PS steam laser cleaning of Si surfaces. Appl Phys A 69, S331-S334 (1999).

13. Leiderer $\mathrm{P}$, Boneberg $\mathrm{J}$, Mosbacher $\mathrm{M}$, Schilling $\mathrm{A}$, Yavas $\mathrm{O}$. Laser cleaning of silicon surfaces. Proc SPIE 3274, 68-78 (1998).

14. Chaoui N, Solis J, Afonso CN, Fourrier T, Muehlberger T et al. A high-sensitivity in situ optical diagnostic technique for laser cleaning of transparent substrates. Appl Phys A 76, 767-771 (2003).

15. Leiderer P, Boneberg J, Dobler V, Mosbacher M, Münzer HJ et 
al. Laser-induced particle removal from Silicon wafers. Proc SPIE 4065, 249-259 (2000).

16. Vereecke G, Röhr E, Heyns MM. Laser-assisted removal of particles on silicon wafers. J Appl Phys 85, 3837-3843 (1999).

17. Lu YF, Zheng YW, Song WD. Laser induced removal of spherical particles from silicon wafers. J Appl Phys 87, 1534-1539 (2000).

18. Wu X, Sacher E, Meunier M. The modeling of excimer laser particle removal from hydrophilic silicon surfaces. J Appl Phys 87, 3618-3627 (2000).

19. Zheng YW, Luk'yanchuk BS, Lu YF, Song WD, Mai ZH. Dry laser cleaning of particles from solid substrates: experiments and theory. J Appl Phys 90, 2135-2142 (2001).

20. Grojo D, Delaporte P, Sentis M, Pakarinen OH, Foster AS. The so-called dry laser cleaning governed by humidity at the nanometer scale. Appl Phys Lett 92, 033108 (2008).

21. Halfpenny DR, Kane DM. A quantitative analysis of single pulse ultraviolet dry laser cleaning. J Appl Phys 86, 6641-6646 (1999).

22. Kane DM, Halfpenny DR. Reduced threshold ultraviolet laser ablation of glass substrates with surface particle coverage: a mechanism for systematic surface laser damage. J Appl Phys 87, 4548-4552 (2000).

23. Mie G. Beiträge zur Optik trüber Medien, speziell kolloidaler Metallösungen. Ann Phys 330, 377-445 (1908).

24. Mosbacher M, Münzer HJ, Zimmermann J, Solis J, Boneberg J et al. Optical field enhancement effects in laser-assisted particle removal. Appl Phys A 72, 41-44 (2001).

25. Kühler P, Puerto D, Mosbacher M, Leiderer P, de Abajo FJG et al. Femtosecond-resolved ablation dynamics of $\mathrm{Si}$ in the near field of a small dielectric particle. Beilstein J Nanotechnol 4, 501-509 (2013).

26. Lu YF, Zhang L, Song WD, Zheng YW, Luk'yanchuk BS. Laser writing of a subwavelength structure on silicon (100) surfaces with particle-enhanced optical irradiation. J Exp Theor Phys Lett 72, 457-459 (2000).

27. Münzer HJ, Mosbacher M, Bertsch M, Zimmermann J, Leiderer $P$ et al. Local field enhancement effects for nanostructuring of surfaces. J Microsc 202, 129-135 (2001).

28. Fischer $\mathrm{CU}$, Zingsheim HP. Submicroscopic pattern replication with visible light. J Vac Sci Technol 19, 881-885 (1981).

29. Deckman HW, Dunsmuir JH. Natural lithography. App/ Phys Lett 41, 377-379 (1982).

30. Burmeister F, Schäfle C, Keilhofer B, Bechinger C, Boneberg J et al. From mesoscopic to nanoscopic surface structures: lithography with colloid monolayers. Adv Mater 10, 495-497 (1998).

31. Kosiorek A, Kandulski W, Chudzinski P, Kempa K, Giersig M. Shadow nanosphere lithography: simulation and experiment. Nano Lett 4, 1359-1363 (2004).

32. Watanabe O, Ikawa T, Hasegawa M, Tsuchimori M, Kawata Y. Nanofabrication induced by near-field exposure from a nanosecond laser pulse. Appl Phys Lett 79, 1366-1368 (2001).

33. Münzer $\mathrm{HJ}$, Mosbacher M, Bertsch M, Dubbers $\mathrm{O}$, Burmeister $F$ et al. Optical near-field effects in surface nanostructuring and laser cleaning. Proc SPIE 4426, 180-183 (2002).

34. Piglmayer K, Denk R, Bäuerle D. Laser-induced surface patterning by means of microspheres. Appl Phys Lett $\mathbf{8 0}$, 4693-4695 (2002).

35. Denk R, Piglmayer K, Bäuerle D. Laser-induced nanopatterning of PET using a-SiO 2 microspheres. Appl Phys A 74,
825-826 (2002).

36. Huang SM, Hong MH, Luk'yanchuk BS, Zheng YW, Song WD et al. Pulsed laser-assisted surface structuring with optical near-field enhanced effects. J Appl Phys 92, 2495-2500 (2002).

37. Lu Y, Chen SC. Nanopatterning of a silicon surface by nearfield enhanced laser irradiation. Nanotechnology 14, 505-508 (2003).

38. Huang SM, Sun Z, Luk'yanchuk BS, Hong MH, Shi LP. Nanobump arrays fabricated by laser irradiation of polystyrene particle layers on silicon. Appl Phys Lett 86, 161911 (2005).

39. Takada H, Obara M. Fabrication of hexagonally arrayed nanoholes using femtosecond laser pulse ablation with template of subwavelength polystyrene particle array. Jpn J Appl Phys 44 7993-7997 (2005).

40. Zhou Y, Hong MH, Fuh JYH, Lu L, Luk'yanchuk BS et al. Direct femtosecond laser nanopatterning of glass substrate by particle-assisted near-field enhancement. Appl Phys Lett 88, 023110 (2006).

41. Brodoceanu D, Landström L, Bäuerle D. Laser-induced nanopatterning of silicon with colloidal monolayers. Appl Phys A 86, 313-314 (2007)

42. Huang SM, Sun Z, Lu YF. Nanofabrication by laser irradiation of polystyrene particle layers on silicon. Nanotechnology $\mathbf{1 8}$, 025302 (2007).

43. Ulmeanu M, Zamfirescu M, Rusen L, Luculescu C, Moldovan A et al. Structuring by field enhancement of glass, $\mathrm{Ag}, \mathrm{Au}$, and Co thin films using short pulse laser ablation. J Appl Phys 106, 114908 (2009).

44. Wang XC, Zheng HY, Tan CW, Wang F, Yu HY et al. Fabrication of silicon nanobump arrays by near-field enhanced laser irradiation. Appl Phys Lett 96, 084101 (2010).

45. Deepak KLN, Grojo D, Charmasson L, Delaporte P, Utéza O et al. Fabrication of microcraters on silicon substrate by UV nanosecond photonic nanojets from microspheres. UVX 2012, 02003 (2013).

46. Juodkazis S, Nishi $\mathrm{Y}$, Misawa $\mathrm{H}$, Mizeikis V, Schecker O et al. Optical transmission and laser structuring of silicon membranes. Opt Express 17, 15308-15317 (2009).

47. Mosbacher M, Dobler V, Bertsch M, Münzer HJ, Boneberg J et al. Laser cleaning of silicon wafers: prospects and problems. Surface Contamination and Cleaning, Vol. 1311 (VSP 2003); http://nbn-resolving.de/urn:nbn:de:bsz:352-opus-27803.

48. Wysocki G, Denk R, Piglmayer K, Arnold N, Bäuerle D. Singlestep fabrication of silicon-cone arrays. Appl Phys Lett $\mathbf{8 2}$, 692-693 (2003).

49. Lang F, Mosbacher M, Leiderer P. Near field induced defects and influence of the liquid layer thickness in Steam Laser Cleaning of silicon wafers. Appl Phys A 77, 117-123 (2003).

50. Ulmeanu M, Petkov P, Ursescu D, Maraloiu VA, Jipa F et al. Pattern formation on silicon by laser-initiated liquid-assisted colloidal lithography. Nanotechnology 26, 455303 (2015).

51. Ulmeanu M, Petkov P, Ursescu D, Jipa F, Harniman R et al. Substrate surface patterning by optical near field modulation around colloidal particles immersed in a liquid. Opt Express 24, 27340-27351 (2016)

52. Guo W, Wang ZB, Li L, Whitehead DJ, Luk'yanchuk BS et al. Near-field laser parallel nanofabrication of arbitrary-shaped patterns. Appl Phys Lett 90, 243101 (2007).

53. McLeod E, Arnold CB. Subwavelength direct-write nanopatterning using optically trapped microspheres. Nat Nanotechnol 


\section{3, 413-417 (2008)}

54. McLeod E, Arnold CB. Array-based optical nanolithography using optically trapped microlenses. Opt Express 17, 3640-3650 (2009).

55. Fardel R, McLeod E, Tsai YC, Arnold CB. Nanoscale ablation through optically trapped microspheres. Appl Phys A 101, 41-46 (2010).

56. Chen ZG, Taflove A, Backman V. Photonic nanojet enhancement of backscattering of light by nanoparticles: a potential novel visible-light ultramicroscopy technique. Opt Express $\mathbf{1 2}$, 1214-1220 (2004).

57. Karakurt I, Boneberg J, Leiderer P, Lopez R, Halabica A, Haglund RF. Transmission increase upon switching of $\mathrm{VO}_{2}$ thin films on microstructured surfaces. Appl Phys Lett 91, 091907 (2007).

58. Karakurt I, Adams $\mathrm{CH}$, Leiderer P, Boneberg J, Haglund RF. Nonreciprocal switching of $\mathrm{VO}_{2}$ thin films on microstructured surfaces. Opt Lett 35, 1506-1509 (2010).

59. Chen LW, Zheng XR, Du ZR, Jia BH, Gu M et al. A frozen matrix hybrid optical nonlinear system enhanced by a particle lens. Nanoscale 7, 14982-14988 (2015).

60. Soh JH, Wu MX, Gu GQ, Chen LW, Hong MH. Temperaturecontrolled photonic nanojet via $\mathrm{VO}_{2}$ coating. Appl Opt 55, 3751-3756 (2016).

61. Jin YJ, Chen LW, Wu MX, Lu XZ, Zhou R et al. Enhanced saturable absorption of the graphene oxide film via photonic nanojets. Opt Mater Express 6, 1114-1121 (2016).

62. Heifetz A, Kong SC, Sahakian AV, Taflove A, Backman V. Photonic nanojets. J Comput Theor Nanosci 6, 1979-1992 (2009).

63. Luk'yanchuk BS, Paniagua-Domínguez R, Minin I, Minin O, Wang ZB. Refractive index less than two: photonic nanojets yesterday, today and tomorrow [Invited]. Opt Mater Express 7, 1820-1847 (2017).

64. Surdo S, Duocastella M, Diaspro A. Nanopatterning with photonic nanojets: review and perspectives in biomedical research. Micromachines 12, 256 (2021).

65. Wang ZB, Guo W, Li L, Luk'yanchuk B, Khan A et al. Optical virtual imaging at $50 \mathrm{~nm}$ lateral resolution with a white-light nanoscope. Nat Commun 2, 218 (2011).

66. Chen LW, Zhou Y, Wu MX, Hong MH. Remote-mode microsphere nano-imaging: new boundaries for optical microscopes. Opto-Electron Adv 1, 170001 (2018).

67. Chen LW, Zhou Y, Zhou R, Hong MH. Microsphere - toward future of optical microscopes. iScience 23, 101211 (2020).

68. Decker M, Staude I. Resonant dielectric nanostructures: a lowloss platform for functional nanophotonics. J Opt 18, 103001 (2016).

69. Zenhausern F, Martin Y, Wickramasinghe HK. Scanning interferometric apertureless microscopy: optical imaging at 10 angstrom resolution. Science 269, 1083-1085 (1995).

70. Knoll B, Keilmann F. Near-field probing of vibrational absorption for chemical microscopy. Nature 399, 134-137 (1999).

71. Hillenbrand R, Taubner T, Keilmann F. Phonon-enhanced light-matter interaction at the nanometre scale. Nature $\mathbf{4 1 8}$, 159-162 (2002).

72. Hillenbrand $R$, Keilmann $F$, Hanarp $P$, Sutherland DS, Aizpurua J. Coherent imaging of nanoscale Plasmon patterns with a carbon nanotube optical probe. Appl Phys Lett 83, 368-370 (2003).

73. Esteban R, Vogelgesang R, Dorfmüller J, Dmitriev A, Rock- stuhl $C$ et al. Direct Near-field optical imaging of higher order plasmonic resonances. Nano Lett 8, 3155-3159 (2008).

74. Jersch J, Dickmann K. Nanostructure fabrication using laser field enhancement in the near field of a scanning tunneling microscope tip. Appl Phys Lett 68, 868-870 (1996).

75. Boneberg J, Tresp M, Ochmann M, Münzer HJ, Leiderer P. Time-resolved measurements of the response of a STM tip upon illumination with a nanosecond laser pulse. Appl Phys $A$ 66, 615-619 (1998)

76. Huber R, Koch M, Feldmann J. Laser-induced thermal expansion of a scanning tunneling microscope tip measured with an atomic force microscope cantilever. Appl Phys Lett 73, 2521-2523 (1998).

77. Boneberg J, Münzer HJ, Tresp M, Ochmann M, Leiderer P. The mechanism of nanostructuring upon nanosecond laser irradiation of a STM tip. Appl Phys A 67, 381-384 (1998).

78. Mai ZH, Lu YF, Huang SM, Chim WK. Mechanism of laser-induced nanomodification on hydrogen-passivated $\mathrm{Si}(100)$ surfaces underneath the tip of a scanning tunneling microscope. $J$ Vac Sci Technol B 18, 1853-1853 (2000).

79. Lu YF, Mai ZH Zheng YW, Song WD. Nanostructure fabrication using pulsed lasers in combination with a scanning tunneling microscope: mechanism investigation. Appl Phys Lett 76, 1200-1202 (2000).

80. Huang SM, Hong MH, Lu YF, Lukỳanchuk BS, Song WD et al. Pulsed-laser assisted nanopatterning of metallic layers combined with atomic force microscopy. J Appl Phys 91, 3268-3274 (2002).

81. Chimmalgi A, Choi TY, Grigoropoulos CP, Komvopoulos K. Femtosecond laser aperturless near-field nanomachining of metals assisted by scanning probe microscopy. Appl Phys Lett 82, 1146-1148 (2003).

82. Chimmalgi A, Grigoropoulos CP, Komvopoulos K. Surface nanostructuring by nano-/femtosecond laser-assisted scanning force microscopy. J Appl Phys 97, 104319 (2005).

83. Leiderer P, Bartels C, König-Birk J, Mosbacher M, Boneberg J. Imaging optical near-fields of nanostructures. Appl Phys Lett 85, 5370-5372 (2004).

84. Nedyalkov NN, Takada H, Obara M. Nanostructuring of silicon surface by femtosecond laser pulse mediated with enhanced near-field of gold nanoparticles. Appl Phys A 85, 163-168 (2006).

85. Nedyalkov N, Sakai T, Miyanishi T, Obara M. Near field distribution in two dimensionally arrayed gold nanoparticles on platinum substrate. Appl Phys Lett 90, 123106 (2007).

86. Imamova S, Nedyalkov N, Dikovska A, Atanasov P, Sawczak $M$ et al. Near field properties of nanoparticle arrays fabricated by laser annealing of thin Au and Ag films. App/ Surf Sci 257, 1075-1079 (2010).

87. Huang WY, Qian W, El-Sayed MA. Gold nanoparticles propulsion from surface fueled by absorption of femtosecond laser pulse at their surface Plasmon resonance. $\mathrm{J} \mathrm{Am} \mathrm{Chem} \mathrm{Soc}$ 128, 13330-13331 (2006).

88. Jamali AA, Witzigmann B, Morarescu R, Baumert $T$, Träger $F$ et al. Local near field assisted ablation of fused silica: an experimental and theoretical study. Appl Phys A 110, 743-749 (2013).

89. Ueno $\mathrm{K}$, Juodkazis $\mathrm{S}$, Shibuya $\mathrm{T}$, Yokota $\mathrm{Y}$, Mizeikis $\mathrm{V}$ et al. Nanoparticle plasmon-assisted two-photon polymerization induced by incoherent excitation source. J Am Chem Soc 130 , 6928-6929 (2008). 
90. Murazawa N, Ueno K, Mizeikis V, Juodkazis S, Misawa H. Spatially Selective nonlinear photopolymerization induced by the near-field of surface plasmons localized on rectangular gold nanorods. J Phys Chem C 113, 1147-1149 (2009).

91. Geldhauser T, Ikegaya S, Kolloch A, Murazawa N, Ueno K et al. Visualization of near-field enhancements of gold triangles by nonlinear photopolymerization. Plasmonics 6, 207-212 (2011).

92. Hubert C, Rumyantseva A, Lerondel G, Grand J, Kostcheev S et al. Near-field photochemical imaging of noble metal nanostructures. Nano Lett 5, 615-619 (2005).

93. Kühler P, de Abajo FJG, Solis J, Mosbacher M, Leiderer P et al. Imprinting the optical near field of microstructures with nanometer resolution. Small 5, 1825-1829 (2009).

94. Kühler P, de Abajo FJG, Leiprecht $P$, Kolloch A, Solis J et al. Quantitative imaging of the optical near field. Opt Express 20, 22063-22078 (2012).

95. Hennemann LE, Kolloch A, Kern A, Mihaljevic J, Boneberg J et al. Assessing the plasmonics of gold nano-triangles with higher order laser modes. Beilstein J Nanotechnol 3, 674-683 (2012).

96. Hanke T, Cesar J, Knittel V, Trügler A, Hohenester $U$ et al. Tailoring spatiotemporal light confinement in single plasmonic nanoantennas. Nano Lett 12, 992-996 (2012).

97. Sun Q, Ueno K, Yu H, Kubo A, Matsuo $Y$ et al. Direct imaging of the near field and dynamics of surface Plasmon resonance on gold nanostructures using photoemission electron microscopy. Light:Sci App/ 2, e118 (2013).

98. Aeschlimann M, Bauer M, Bayer D, Brixner T, de Abajo FJG et al. Adaptive subwavelength control of nano-optical fields. Nature 446, 301-304 (2007).

99. Fiutowski J, Maibohm C, Kjelstrup-Hansen J, Rubahn HG. Laser ablation of polymer coatings allows for electromagnetic field enhancement mapping around nanostructures. Appl Phys Lett 98, 193117 (2011).

100. Metzger B, Hentschel M, Giessen $H$. Probing the near-field of second-harmonic light around plasmonic nanoantennas. Nano Lett 17, 1931-1937 (2017).

101. Gonçalves MR, Marti O. Experimental observation of the scattering of light by planar metallic nanoparticles. New J Phys $\mathbf{5}$, 160.1-160.14 (2003).

102. Kolloch A, Leiderer P, Ibrahimkutty S, Issenmann D, Plech A. Structural study of near-field ablation close to Plasmon-resonant nanotriangles. J Laser App/ 24, 042015 (2012).

103. Boneberg J, König-Birk J, Münzer HJ, Leiderer $P$, Shuford KL et al. Optical near-fields of triangular nanostructures. Appl Phys A 89, 299-303 (2007).

104. Kolloch A, Geldhauser T, Ueno K, Misawa H, Boneberg J et al. Femtosecond and picosecond near-field ablation of gold nanotriangles: nanostructuring and nanomelting. Appl Phys A 104, 793-799 (2011).

105. Kolloch A. Plasmon resonances for sub-100 nm silicon ablation: quantitative measurement and nanometer-scale ablation mechanism (University of Konstanz, Konstanz, 2012); http://kops.uni-konstanz.de/handle/123456789/23193.

106. Dickreuter S, Gleixner J, Kolloch A, Boneberg J, Scheer E et al. Mapping of plasmonic resonances in nanotriangles. Beilstein J Nanotechnol 4, 588-602 (2013).

107. Perassi EM, Hernandez-Garrido JC, Moreno MS, Encina ER, Coronado EA et al. Using highly accurate $3 \mathrm{D}$ nanometrology to model the optical properties of highly irregular nanoparticles: a powerful tool for rational design of plasmonic devices. Nano Lett 10, 2097-2104 (2010).

108. Nagy BJ, Pápa Z, Péter L, Prietl C, Krenn JR et al. Near-fieldinduced femtosecond breakdown of plasmonic nanoparticles. Plasmonics 15, 335-340 (2020).

109. Scheffler CM, Word RC, Könenkamp R. Controlling electric field and photoemission at the tips of triangular gold antennas. Plasmonics 16, 371-377 (2021).

110. Eversole D, Luk'yanchuk B, Ben-Yakar A. Plasmonic laser nanoablation of silicon by the scattering of femtosecond pulses near gold nanospheres. Appl Phys A 89, 283-291 (2007).

111. Hubenthal $F$, Morarescu R, Englert L, Haag L, Baumert T et al. Parallel generation of nanochannels in fused silica with $a$ single femtosecond laser pulse: exploiting the optical near fields of triangular nanoparticles. Appl Phys Lett 95, 063101 (2009).

112. Morarescu R, Englert L, Kolaric B, Damman P, Vallée RAL et al. Tuning nanopatterns on fused silica substrates: a theoretical and experimental approach. J Mater Chem 21, 4076-4081 (2011).

113. Habenicht $A$, Olapinski $M$, Burmeister $F$, Leiderer $P$, Boneberg J. Jumping nanodroplets. Science 309, 2043-2045 (2005).

114. Vogelgesang R, Dmitriev A. Real-space imaging of nanoplasmonic resonances. Analyst 135, 1175-1181 (2010).

115. Schuller JA, Barnard ES, Cai WS, Jun YC, White JS et al. Plasmonics for extreme light concentration and manipulation. Nat Mater 9, 193-204 (2010).

116. Hashimoto S, Werner D, Uwada T. Studies on the interaction of pulsed lasers with plasmonic gold nanoparticles toward light manipulation, heat management, and nanofabrication. J. Photochem Photobiol C:Photochem Rev 13, 28-54 (2012).

117. Boulais E, Lachaine R, Hatef A, Meunier M. Plasmonics for pulsed-laser cell nanosurgery: fundamentals and applications. J Photochem Photobiol C:Photochem Rev 17, 26-49 (2013).

118. Merlen A, Lagugné-Labarthet $F$. Imaging the optical near field in plasmonic nanostructures. Appl Spectrosc 68, 1307-1326 (2014).

119. Terakawa M, Nedyalkov NN. Near-field optics for nanoprocessing. Adv Opt Technol 5, 17-28 (2016).

120. Nedyalkov N, Sakai T, Miyanishi T, Obara M. Near field properties in the vicinity of gold nanoparticles placed on various substrates for precise nanostructuring. J Phys D:App/ Phys 39, 5037-5042 (2006).

121. Hashimoto S, Uwada T, Hagiri M, Takai H, Ueki T. Gold nanoparticle-assisted laser surface modification of borosilicate glass substrates. J Phys Chem C 113, 20640-20647 (2009).

122. Hashimoto S, Uwada T, Hagiri M, Shiraishi R. Mechanistic aspect of surface modification on glass substrates assisted by single shot pulsed laser-induced fragmentation of gold Nanoparticles. J Phys Chem C 115, 4986-4993 (2011).

123. Harrison RK, Ben-Yakar A. Role of near-field enhancement in plasmonic laser nanoablation using gold nanorods on a silicon substrate. Opt Express 18, 22556-22571 (2010).

124. Harrison RK, Ben-Yakar A. Role of near-field enhancement in plasmonic laser nanoablation using gold nanorods on a silicon substrate: reply. Opt Express 19, 6179-6181 (2011).

125. Boulais E, Robitaille A, Desjeans-Gauthier P, Meunier M. Role of near-field enhancement in plasmonic laser nanoablation using gold nanorods on a silicon substrate: comment. Opt Express 19, 6177-6178 (2011).

126. Robitaille A, Boulais É, Meunier M. Mechanisms of 
plasmon-enhanced femtosecond laser nanoablation of silicon. Opt Express 21, 9703-9710 (2013).

127. von der Linde D, Sokolowski-Tinten K, Bialkowski J. Laser-solid interaction in the femtosecond time regime. Appl Surf Sci 109/110, 1-10 (1997).

128. Bonse J, Baudach S, Krüger J, Kautek W, Lenzner M. Femtosecond laser ablation of silicon-modification thresholds and morphology. Appl Phys A 74, 19-25 (2002).

129. Juan ML, Righini M, Quidant R. Plasmon nano-optical tweezers. Nat Photonics 5, 349-356 (2011).

130. Kotsifaki DG, Chormaic SN. Plasmonic optical tweezers based on nanostructures: fundamentals, advances and prospects. Nanophotonics 8, 1227-1245 (2019).

131. Wang ZB, Hong MH, Luk BS'yanchuk, Lin $Y$, Wang QF et al. Angle effect in laser nanopatterning with particle-mask. $J$ Appl Phys 96, 6845-6850 (2004).

132. Pena A, Wang ZB, Whitehead D, Li L. Direct writing of micro/nano-scale patterns by means of particle lens arrays scanned by a focused diode pumped $\mathrm{Nd}$ : $\mathrm{YVO}_{4}$ laser. Appl Phys A 101, 287-295 (2010).

133. Tanaka Y, Obara G, Zenidaka A, Terakawa M, Obara M.
Femtosecond laser near-field nanoablation patterning using Mie resonance high dielectric constant particle with small size parameter. Appl Phys Lett 96, 261103 (2010).

\section{Acknowledgements}

We have benefitted from various joint projects and numerous enlightening discussions with our colleagues in the field of laser light interaction with surfaces. In particular, we would like to mention the close collaboration within the TMR Research Network ERB FMRX-CT98-0188 "Modelling and Diagnostics of Pulsed Laser-Solid Interactions. Applications to Laser Cleaning" with the groups of Carmen Afonso, Jan Siegel and Xavier Solis (Madrid), Dieter Bäuerle (Linz) and Roland Oltra (Dijon), and also with Andrew C. Tam (San Jose), Minghui Hong and Boris Luk'yanchuk (Singapore), A. Pack and R. Wannemacher (Chemnitz), and Hiroaki Misawa, Kosei Ueno, and Saulius Juodkazis (Sapporo) and their teams. In our group in Konstanz we are especially indebted to Oguz Yavas, Hajo Münzer, Mario Mosbacher, Michael Ochmann, Juliane König-Birk, Andreas Kolloch, Christof Bartels, Volker Dobler, Simon Dickreuter, Julia Gleixner, and Paul Kühler.

\section{Competing interests}

The authors declare no competing financial interests. 